\title{
Idiopathic Pulmonary Arterial Hypertension in Children: A Review
}

\author{
Gerson A. Valencia · Usha Krishnan
}

Received: January 4, 2017 / Published online: March 23, 2017

(C) The Author(s) 2017. This article is an open access publication

\begin{abstract}
Pediatric pulmonary hypertension $(\mathrm{PH})$ is a heterogeneous disorder that leads to significant morbidity and mortality if left untreated. The Nice WHO classification from 2013 classifies PH into five groups: broadly, Group I pulmonary arterial hypertension $(\mathrm{PAH})$, which includes idiopathic PAH, PAH associated with congenital heart disease and others; Group II comprises post-capillary PH (left heart disease), Group III comprises lung disease, Group IV thromboembolic disease and Group V miscellaneous causes of $\mathrm{PH}$. The majority of pediatric $\mathrm{PH}$ comprise either Group I or Group III PH, but often children manifest features of several groups and are treated with targeted therapy. PAH in children requires a multifaceted approach. The pathogenesis is complex and it involves pulmonary vasoconstriction, endothelial dysfunction, inflammation and cell proliferation. Large multicenter and international registries have been formed with the aim of furthering understanding of this disease and developing
\end{abstract}

Enhanced Content To view enhanced content for this article go to http://www.medengine.com/Redeem/ 25F7F060375EB526.

G. A. Valencia $(\bowtie) \cdot$ U. Krishnan

Department of Pediatrics (Pediatric Cardiology), Columbia University Medical Center, College of Physicians and Surgeons, New York, USA e-mail: gav2115@cumc.columbia.edu appropriate therapeutic guidelines for managing pediatric $\mathrm{PH}$. In this review, we describe the epidemiology, pathophysiology, clinical presentation, diagnosis and management of pediatric pulmonary hypertension.

Keywords: Idiopathic pulmonary hypertension; Pediatric pulmonary hypertension; Review

\section{INTRODUCTION}

Pediatric pulmonary arterial hypertension (PAH) is recognized as a progressive and fatal illness. There have been multiple advances in the field within the last two decades aimed at prolonging survival rates and improving quality of life. Despite all these efforts, PAH still remains an important cause of morbidity and mortality in children [1-3].

Pulmonary hypertension is estimated to affect $<10$ cases per million children, with an incidence of 1-2 new cases/million per year. There are multiple registries around the world that have included children and adults with PAH. The Tracking Outcomes and Practice in Pediatric Pulmonary Hypertension (TOPP) registry is a global, prospective study designed to provide information about demographics, treatment, and outcomes in pediatric pulmonary hypertension [4]. In the United States, 
the Registry to Evaluate Early And Long-Term PAH Disease Management (REVEAL) registry is a multicenter, observational study which included 216 patients $<18$ years of age with Group I pulmonary arterial hypertension (PAH): $56 \%$ of these patients were affected by idiopathic PAH and familial PAH with slight female predominance $(60 \%), 36 \%$ were associated with congenital heart disease (APAH-CHD) and 8\% were associated with other causes of $\mathrm{PAH}$ such as connective tissue disease (CTD), portal hypertension and persistent pulmonary hypertension of the newborn (PPHN) [5].

The overall outlook for PAH has dramatically improved over the last two decades since the discovery of epoprostenol in 1976, a synthetic prostacyclin that was finally approved for the treatment of PAH in 1995 leading to a significant improvement in survival rates [6-8]. Early reports of children affected with PAH showed a median survival of only 10 months [9]. In the modern era, with early diagnosis and initiation of therapy, survival at 1, 2 and 3 years has been reported to be $99 \%, 96 \%$ and $84 \%$ in children with PAH [10]. Patients with Eisenmenger syndrome (ES) have better survival compared to IPAH with most ES patients surviving into their third-fourth decade, most likely due to the presence of a pop-off shunt [11]. The right ventricle (RV) in ES is subjected to systemic pressures from birth as the pulmonary vascular resistance (PVR) never regresses to normal levels. Thus, the RV musculature appears to adapt to high pressures (similar to fetal life) and remains capable of sustaining its systolic function despite pumping against high PVR for much longer than in IPAH where the RV is subject to elevated PVR much later, and hence fails earlier than in patients with ES [12].

Continuous efforts are being made to bring awareness of the disease leading to early diagnosis, decreased morbidity and improved survival. Pediatric patients across North America are being enrolled in the Pediatric Pulmonary Hypertension Network (PPHNET) Informatics Registry, a pediatric clinical registry that will include a large number of children with $\mathrm{PH}$. This will lead to improved understanding of childhood PH and help guide therapy. Novel translational research ideas that focus on the molecular and genetic basis of $\mathrm{PH}$ are being studied which will clarify the pathogenesis of the disease and also assist in tailoring therapy based on the genetic changes as well as developing newer targeted therapies with greater efficacy for the treatment of PAH [13-15].

The main focus of this review will be on Idiopathic Pulmonary Arterial Hypertension (IPAH), reviewing current available therapies and those undergoing investigation. We must acknowledge that many pediatric patients have characteristics of different WHO groups of $\mathrm{PH}$ and may not wholly fit into one group. For the purposes of this review, other major causes of $\mathrm{PH}$ such as congenital heart disease, connective tissue disorder and parenchymal lung disease will be excluded.

This article is based on previously conducted studies and does not involve any new studies of human or animal subjects performed by any of the authors. In this report, the authors discuss several medications and therapies which are not FDA-approved for pediatric use, and use of these medications for pediatric patients is to be done only at centers with experience and expertise for caring for these patients.

\section{DEFINITION}

Pulmonary arterial hypertension (PAH) in children is defined as a resting mean pulmonary artery pressure (mPAP) $\geq 25 \mathrm{mmHg}$ with pulmonary arterial wedge pressure (PAWP) $<15 \mathrm{mmHg}$ and pulmonary vascular resistance indexed (PVRI) $>3$ woods units $\times \mathrm{m}^{2}$ in patients with two ventricles [15]. Blood pressure in children also varies with age compared to adults, and as a result a pulmonary to systemic pressure ratio of $>0.4$ is also considered indicative of $\mathrm{PAH}$ [16]. $\mathrm{PAH}$ is particularly challenging due to its multifactorial nature and it can often be the common denominator of multiple conditions. The updated WHO clinical classification demonstrates the diversity and complexity of pediatric pulmonary hypertension [17].

Most children with $\mathrm{PH}$ belong to WHO Group I, II and III PH with fewer thromboembolic or multifactorial (Group IV or V) $\mathrm{PH}$. 
Pulmonary arterial hypertension (PAH) is a synonym of "pre-capillary" pulmonary hypertension and encompasses IPAH and associated PAH (APAH) secondary to congenital heart disease (CHD), connective tissue disease (CTD) and persistent pulmonary hypertension of the newborn (PPHN) are included in Group $1 \mathrm{PH}$ [18]. Unlike the adult population in which CTD and left ventricular diastolic dysfunction (WHO Group II) are important causes of PH, in children, IPAH/HPAH, congenital heart disease (CHD) and chronic lung disease (CLD) are more frequent causes of $\mathrm{PH}$. This is also exponentially changing, as more patients with CHD survive into adulthood $[19,20]$.

\section{PATHOGENESIS OF PEDIATRIC PAH}

Genetic predisposition to hereditary PAH was first reported in 1954 [21], and since then, multiple genes have been discovered and associated with PAH [22-25] (Table 1). HPAH has an autosomal dominant mode of inheritance with the defect in most cases localized to a region on chromosome 2q31-33 [26, 27]. The transforming growth factor B (TGFB) family of receptors has been studied extensively, particularly the bone morphogenic protein receptor (BMPR2) associated with HPAH [28-30]. BMPR2 mutations are seen in over $80 \%$ of patients with $\mathrm{HPAH}$, being up to $25 \%$ de novo mutations. Interestingly, only about $20 \%$ of subjects with a BMPR2-detected mutation develop the disease and the clinical presentation is variable even within the same family. There is a higher incidence of HPAH in females compared to males, leading to speculation that the male fetuses might die in utero [31-33]. Furthermore, sex hormones can modulate NO signaling pathways and circulating endothelin-1 levels. Alteration in estrogen metabolism is linked to increased risk of PAH penetrance in female, but not male, BMPR2 carriers. On the other hand, men with IPAH/HPAH have higher estradiol and low dehydroepiandrosterone sulfate levels which have has been associated with disease severity [34].

Channelopathies have also been described in IPAH and HPAH. KCNK3, a potassium channel that is sensitive to hypoxia, plays an important role in pulmonary vascular tone. Heterozygous mutation of KCNK3 is associated with regulation of vascular remodeling and abnormal vascular proliferation of pulmonary vessels [35]. Other mutations such as activin receptor-like kinase 1 (ALK-1) located in chromosome 12 and endoglin (ENG) on chromosome 9 have been described in patients with hereditary hemorrhagic telangiectasia (HHT) and HPAH [36]. The SMAD8 gene on chromosome 13 , which is involved in the TGF-beta/BMP signaling, has also been associated in patients with PAH [37]. Caveolin (CAV-1) gene mutation has also been recently reported in association with activation of proliferative and anti-apoptotic pathways leading to vascular injury [38, 39]. Genetic testing can be useful in children with IPAH or in families with HPAH to allow for definition of etiology and identification of family members at risk to be able to best counsel the family [40]. Testing should start with the proband and family members should be tested for the mutation expressed in the affected patient $[15,41]$.

IPAH can present in the neonatal period or infancy, and is often diagnosed and treated as persistent pulmonary hypertension of the newborn (PPHN). For this reason, when $\mathrm{PAH}$ persists beyond the first few weeks of life, one must suspect early presentation of IPAH. In these children, lung histopathology is very similar to changes seen in IPAH at an older age [42].

The progression and phenotypic variability of PAH may be affected by multifactorial factors such as genetic background, epigenetic changes, gender and other extraneous factors such as infection and inflammation. Genetically susceptible individuals are more likely to progress into the classic phenotype. Epigenetic modifications may aggravate the disease severity. Three main types of epigenetic regulation involving DNA methylation, histone modification and microRNA (miRNA) have been described in the pathogenesis of PAH [43]. The exact mechanism of the pathogenesis of PAH has not been completely elucidated. Its complexity involves imbalance of vasogenic mediators leading to vasoconstriction, endothelial cell dysfunction, smooth muscle cell proliferation, 
Table 1 Genetic mutations associated with PAH

\begin{tabular}{|c|c|}
\hline Gene Name & Specialized Information \\
\hline \multirow[t]{3}{*}{$B M P R 2$} & TGF- $\beta$ receptor superfamily member \\
\hline & $\geq 80 \%$ of familial cases \\
\hline & $15-25 \%$ of IPAH cases \\
\hline \multirow[t]{3}{*}{$A L K 1$} & TGF-ßreceptor superfamily member \\
\hline & PAH associated with familial HHT \\
\hline & Not known to occur distinct from HHT \\
\hline \multirow[t]{3}{*}{ Endoglin } & TGF- $\beta$ receptor superfamily member \\
\hline & PAH associated with familial HHT \\
\hline & Not known to occur distinct from HHT \\
\hline \multirow[t]{2}{*}{ SMAD9 } & TGF- $\beta$ superfamily downstream signaling molecule (canonical signaling pathway) \\
\hline & Encodes SMAD8 \\
\hline \multirow[t]{2}{*}{$C A V 1$} & Encodes caveolin-1, relevant to caveolar structure as well as nitric oxide signaling \\
\hline & Exact estimate of frequency among PAH patients yet to be determined \\
\hline \multirow[t]{2}{*}{$K C N K 3$} & Encodes TASK-1, a $\mathrm{pH}$ sensitive potassium channel \\
\hline & Exact estimate of frequency among PAH patients yet to be determined \\
\hline \multirow[t]{3}{*}{$E I F 2 A K 4(G C N 2)$} & Association with recessive and sporadic forms of PVOD and $\mathrm{PCH}$ \\
\hline & Encodes a eukaryotic translation initiation factor superfamily member \\
\hline & Exact estimate of frequency among PVOD and $\mathrm{PCH}$ patients yet to be determined \\
\hline
\end{tabular}

Adapted from [39]

All genes are associated with autosomal dominant familial disease except for EIF2AK4, which is associated with autosomal recessive PVOD and $\mathrm{PCH}$

HHT hereditary hemorrhagic telangiectasia; IPAH idiopathic pulmonary arterial hypertension; $P A H$ pulmonary arterial hypertension; $P C H$ pulmonary capillary hemangiomatosis; $P V O D$ pulmonary veno-occlusive disease; and TGF- $\beta$ transforming growth factor- $\beta$

altered mechanisms of apoptosis, inflammation, thrombosis and molecular deviations, as shown in Fig. 1. As more elements involved in this complex process are uncovered, further innovative studies are being carried out in animal and cellular models [44, 45].

\section{Endothelial Dysfunction}

The endothelium is vital for maintaining vascular tone, homeostasis, leukocyte trafficking, transduction of luminal signals to abluminal vascular tissues, production of growth factors, and cell signals with autocrine and paracrine effects and barrier function. Endothelial dysfunction leads to exposure of different cytokines into the vascular wall, leading to humoral imbalance, endothelial cell proliferation and increased coagulability, resulting in medial hypertrophy and hyperplasia [46].

\section{Cell Proliferation and Apoptosis}

More attention has been directed towards cell growth compared to vasoconstriction alone as we gain more knowledge in molecular biology. 


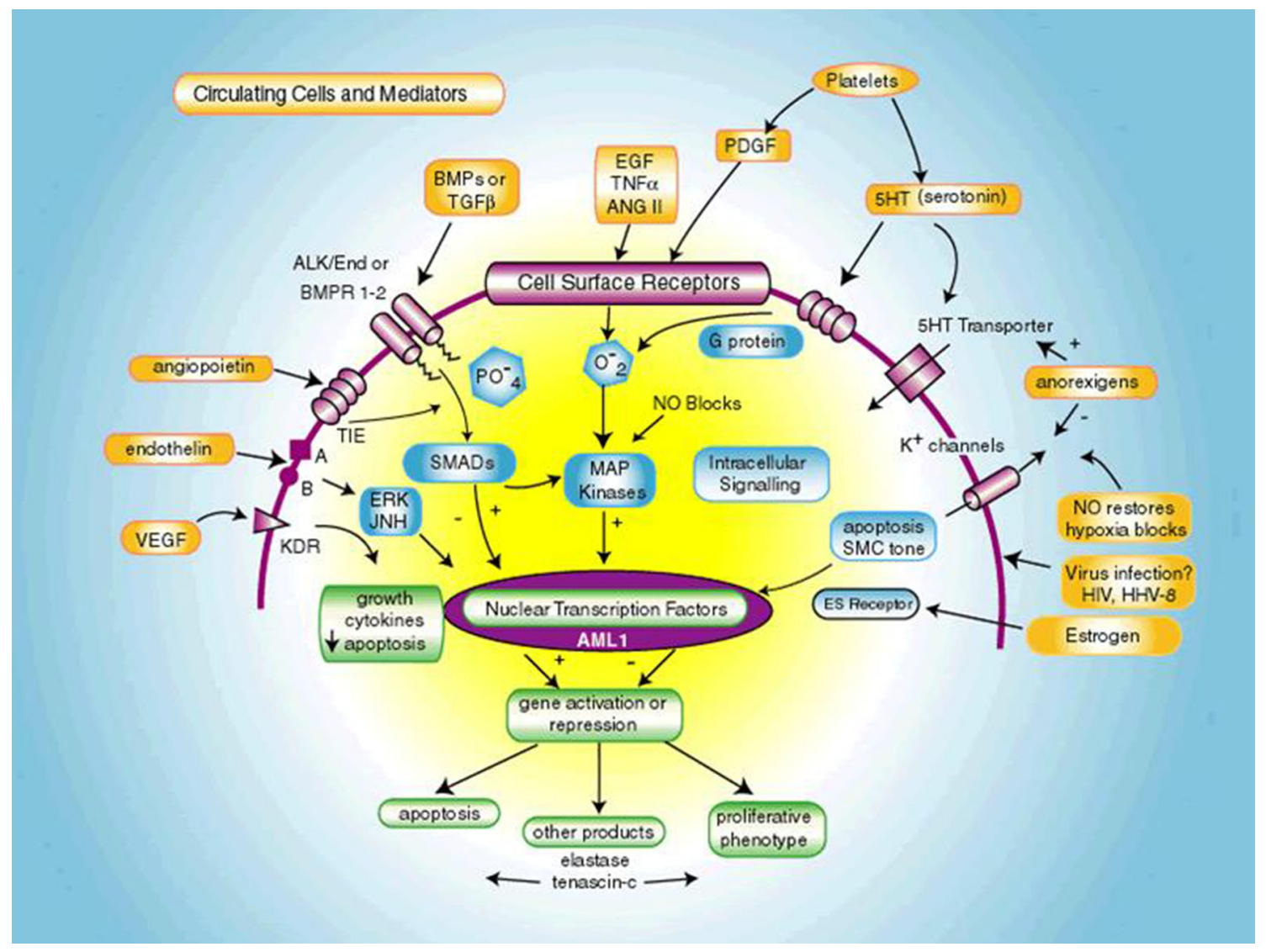

Fig. 1 Some cellular processes implicated in the pathogenesis of primary $\mathrm{PH}(\mathrm{PPH})$. Extracellular mediators and cells (platelets) are highlighted in yellow, cell surface receptors and ion channels in purple, intracellular signaling in blue, and nuclear responses in green. VEGF indicates vascular endothelial growth factor; its receptor is KDR. Intracellular transduction of this pathway is poorly understood. Endothelin is vasoactive and a mitogen, acting through $\mathrm{Ca} 2$ channels and ERK/Jun kinases. TIE is the angiopoietin receptor, a system found to be upregulated in pulmonary vascular disease. Alk1 and BMPR1-2 are receptors of the TGF- $\beta$ superfamily, and BMP indicates bone morphogenetic protein. Alk1 mutations cause hereditary hemorrhagic telangiectasia and some cases of

Many substances, including serotonin (5-HT), platelet-derived growth factor (PDGF), epidermal growth factor (EGF), and vascular endothelial growth factor (VEGF) have direct associations with abnormal cell proliferation and migration of pulmonary artery vascular cells, playing an important role in vascular remodeling. Mutations in BMPR2, ALK-1 and
PPH. Epidermal growth factor $(E G F)$, tumor necrosis factor $(T N F)-\alpha$, angiotensin II $(A N G I I)$, and platelet-derived growth factor $(P D G F)$ are all proliferative stimuli that act through tyrosine kinase receptors and are partially transduced by intracellular oxidant species. In the intracellular domain, SMADs are regulatory proteins that activate nuclear transcription factors and interact with MAP kinases. AML1 is a nuclear transcription factor of potential importance. Elastase, downstream of AML1, has been implicated in vascular disease in experimental animals. Viral proteins are found in vascular lesions in the lungs of patients with $\mathrm{PAH}$, raising the possibility that they participate in its pathogenesis. Adapted from [44]

endoglin are also associated with vascular remodeling [47]. Damage to endothelial cells triggers apoptotic mechanisms leading to mature vascular lesions composed of endothelial cells, smooth muscle cells and apoptotic cells. Endothelial and SMCs also demonstrate mitochondrial abnormalities in PAH patients, which lead to a shift in metabolism favoring 
glycolysis for ATP generation and possibly altering the apoptosis potential [48, 49]. Tyrosine kinase inhibitors (TKI) have been studied for the treatment of PAH. Imatinib, a TKI used for the treatment of CML is also a platelet-derived growth factor (PDFR) receptor inhibitor which showed initial improvement in clinical end-points like World Health Organization functional class (WHO-FC), 6MWDT and pulmonary hemodynamics. Its use is limited due to significant adverse effects reported with long-term use, including syncope, worsening PAH in $4.9 \%$ of patients, and subdural hematoma in up to $4.2 \%$ of patients receiving concomitant anticoagulation [50]. Other TKIs (sorafenib and dasatinib) have also been associated with myocardial damage and worsening PAH [51-53].

\section{Inflammation and Thrombosis}

Different inflammatory processes have been associated with $\mathrm{PAH}$, and the elevation of inflammatory indicators such as C-reactive protein (CRP), interleukin-1 beta, interleukin-6, TNF $\alpha$ have been associated with worse outcome in PAH $[54,55]$. Endothelial dysfunction and inflammation predispose to platelet aggregation and in situ thrombosis. The shear stress or vascular injury can induce up-regulation of cell adhesion molecules that can attract inflammatory mediators (monocytes/macrophages, lymphocytes) to endothelial cells which can contribute to vascular remodeling. Use of anticoagulants has been shown to reduce the incidence of thrombosis both in IPAH as well as chronic thromboembolic $\mathrm{PH}[56,57]$.

\section{Vasoconstriction}

Vasoconstriction is not a uniform process: there is an imbalance of multiple vasoactive substances that lead to decreased relaxation of the pulmonary vasculature, increasing the afterload of the right ventricle. Early histopathologic studies by Heath and Edwards in patients with IPAH showed moderate medial hypertrophy, concentric intimal fibrosis, vascular dilation lesions, plexiform lesions and vascular necrosis.
This was later described as "vasospastic pulmonary hypertension" present in children with hyper-reactive lung vessels [58, 59]. This mechanism was the foundation for the initial treatment of patients with PAH.

Vascular remodeling in PAH will lead to elevated pulmonary vascular resistance (PVR). Normally, PVR drops by half within the first two days of life in full-term newborns. Failure of PVR to drop is associated with multiple factors such as abnormal lung development, maldevelopment of the pulmonary vasculature, premature delivery, mode of delivery, meconium aspiration, maternal fever, maternal pulmonary disease and maternal use of selective serotonin update inhibitors [60-62]. In older children with IPAH, intimal hyperplasia and occlusive changes are found in pulmonary arterioles. In contrast to adults, children have more smooth muscle cell (SMC) hypertrophy, less intimal fibrosis and fewer plexiform lesions. With increasing age, intimal fibrosis and plexiform lesions are more frequent.

There are three important pathways studied in association with pulmonary vasoconstriction: the nitric oxide pathway, the endothelin pathway and the prostacyclin pathway.

a) Nitric oxide pathway: Nitric oxide (NO) is synthesized in the endothelium by endothelial nitric oxide synthase (eNOS), playing an important role in regulating vascular tone. NO then activates the enzyme soluble guanylate cyclase (sGC) which catalyzes the production of cyclic guanosine monophosphate (cGMP), a second messenger that results in activation of cGMP-dependent protein kinases (PKGs), triggering a cascade of reactions that lowers intracellular calcium leading to vasodilation. Phosphodiesterase 5 (PDE-5) lowers cGMP levels in platelets and vascular smooth muscle cells contributing to a powerful negative feedback on NO/cGMP/PKG signaling [63]. This sets the physiologic ground for PDE-5 inhibitors. Some children have increased expression of PDE5 enzyme, leading to degradation of cGMP and vasoconstriction [64]. PDE5 inhibitors replenish cGMP and act as rescue agents preventing rebound $\mathrm{PAH}$ while weaning inhaled NO, 
and also act as potent pulmonary vasodilators [65]. Some forms of PAH have also reduced bioavailability of endothelial NO, either because of reduced eNOS expression or secondary to oxidative stress leading to vascular remodeling [66, 67]. There are other substances that can also inhibit eNOS production such as asymmetric dimethyl arginine (ADMA) in infants with persistent pulmonary hypertension [68].

b) Endothelin pathway: Endothelin (ET)-1, is a potent vasoconstrictor. ET-1 acts via ETA and ETB receptors on SMC. ETA receptors are located on SMC where they mediate vasoconstriction and ETB receptors are located on both SMC and endothelial cells, where they may mediate vasodilation or vasoconstriction. There seems to be no added advantage to selective ETA inhibition, suggesting that the relative expression of the two receptors in disease states may play a role in the pathogenesis PAH. High circulating levels of ET-1 correlate with disease severity in $\mathrm{PAH}$ patients. There is upregulation of ETB receptors in patients with $\mathrm{PH}$ associated with fibrogenesis and cell proliferation [69].

c) Prostacyclin (PGI2) pathway: Prostacyclin is synthesized in the arachidonic acid (AA) pathway, by cyclooxygenase (COX) and prostacyclin (PGI2) synthase. Prostacyclin stimulates the PGI2 (IP) receptor on vascular smooth muscle cells, resulting in increased intracellular cyclic adenosine monophosphate (cAMP) and ultimately vasodilation [70]. The vasodilatory effects of prostacyclin were first described by Vane et al. in 1976, initially referred as "prostaglandin $X^{\prime \prime}$, they described its potent effect on platelet aggregation and smooth muscle relaxation [71]. PGI2 synthase levels are decreased in patients with PAH leading to an imbalance between AA and TXA2. PGI2 also inhibits thromboxane A2 (TXA2) which is a potent vasoconstrictor and platelet aggregator, and also has an important anti-proliferative effect on the vascular smooth muscle. Epoprostenol was the first synthetic prostacyclin used in the treatment of PAH and still remains as an important therapeutic option in patients with severe PAH [15, 72].

\section{Molecular mechanisms of pulmonary artery remodeling}

The excessive vascular cell proliferation is a feature common to all $\mathrm{PH}$ groups, affecting all vessel layers leading to a decrease of the vessel lumen which translates into higher right ventricle afterload. ET-1 activates the mitogen-activated protein kinase (MAPK) pathway, and c-fos and c-jun genes that promote growth signaling and control cell survival and differentiation. PGI2 increases cAMP production which inhibits myosin light chain kinase (MLCK) leading to SMC relaxation. cAMP also has anti-proliferative effects. The transforming growth factor $\beta$ (TGF- $\beta$ ) signaling pathway regulates cell growth and differentiation. Transcription factors including hypoxia inducible factor $($ Hif- $1 \alpha)$, suppressor or cytokine signaling 3 (SOCS3) and nuclear factor kappa B (NF- $\mathrm{KB}$ ) are known regulators or pulmonary artery smooth muscle cell (PASMC) proliferation. Increased expression of Oct- 4 , a novel transcription factor expressed in hypoxic cells and pulmonary artery SMCs, is suggested to play an important role in the development and progression of vascular remodeling. Notch-3 mRNA regulates pulmonary arterial SMC homeostasis, and this gene is overexpressed in $\mathrm{PAH}$ patients, affecting SMC proliferation and vessel remodeling. DNA-binding protein inhibitors (Id) family are another group of transcription factors that may act cooperatively in regulating BMP-dependent SMC proliferation due to chronic hypoxia. There are also epigenetic modifications (histone modifications, DNA methylation and RNA interference) that can selectively activate or inactivate cell growth, proliferations and apoptosis controlling genes. This provides a different insight to the pathophysiology of PAH leading to new treatment strategies [73].

Right ventricular adaptation: The increased afterload from pulmonary artery vasoconstriction and vascular remodeling triggers compensatory RV mechanisms. The RV initially dilates 
and the muscle hypertrophies with preserved systolic function. As the RV dilates, tricuspid regurgitation (TR) increases related to tricuspid valve annular dilation and valve non-coaptation. There is RV volume overload and pressure overload as PAH progresses affecting the interventricular interactions. There is also prolongation of the RV ejection time beyond the LV contraction, causing shifting of the interventricular septum (IVS) toward the left ventricle in both systole and diastole, affecting ventricular filling, function and cardiac output.

\section{CLINICAL PRESENTATION}

Evaluation of infants and children with PAH is always challenging. There are multiple areas of development that must be taken into account when evaluating children. This was well characterized by the Pediatric Task Force of the Pulmonary Vascular Research Institute (PVRI) in Panama 2011, where a functional classification for pediatric pulmonary hypertension was developed, considering individual milestones according to age [74]. Often, the signs and symptoms of PAH are vague and may be treated as other systemic disorders before evaluating for $\mathrm{PAH}$. Dyspnea and fatigue are the most frequent symptoms in IPAH. Dyspnea occurs during physical activity as a result of an inability to increase cardiac output with increased oxygen demand. In pediatrics, failure to thrive is considered as a red flag for chronic illness and is one of the most important signs in children presenting with IPAH. This is more noticeable in children younger than 5 years of age who present with growth impairment. Furthermore, there is increased caloric expenditure and malabsorption in the context of cardiac cachexia due to congestive heart failure [75]. Growth and development are important tools to assess the efficacy of therapy [75]. Children can present with tachycardia and tachypnea as signs of cardiac failure. Cyanosis at baseline or with exertion is commonly seen in patients with right to left shunts at baseline or shunts that reverse with exertion due to increased right-sided pressures. In IPAH, cyanosis occurs in the presence of an atrial shunt. Chronic and worsening cyanosis will lead to high hematocrit. Polycythemia is associated with headaches and increased risk of thrombosis. Hemoptysis can occur secondary to clotting disorders, pulmonary infarcts with secondary arterial thrombosis, in patients with HHT, due to pulmonary telangiectasia and, in some patients, because of poorly monitored anticoagulation therapy.

Children with severe right atrial enlargement and increased right atrial pressure are at risk for supraventricular arrhythmias (SVA). Patients with SVA have a higher risk for clinical deterioration and death, and therefore a history of tachycardia or palpitations is important [76]. Syncope is an alarming sign of IPAH, more common in children than in adults, being present in up to $31 \%$ of children with IPAH [4]. Syncope is often post-exertional but often reported when lifting up heavy objects. Syncope is described as a poor prognostic factor in adult $\mathrm{PAH}$, it is often the initial presenting symptom in children and may actually indicate vasoresponsiveness. Syncope may be manifest early in the morning while waking up, or triggered by inflammation or other vasoactive stimuli. Peripheral vasodilation induced by exercise possibly exacerbates this condition. Children with IPAH have also been mistakenly treated for seizure disorders, and these episodes are usually associated with exercise when pulmonary pressures rise significantly and, in the absence of intracardiac shunting, cardiac output is compromised. Izzo et al. recently reported a case of a 4 year old with IPAH who was initially diagnosed as refractory nocturnal seizures. Nocturnal syncope is probably related to nocturnal hypoxia associated with airway obstruction which can also trigger a pulmonary hypertensive crisis $[4,77,78]$.

The clinical examination of a child with IPAH can give many clues to the presence of RV hypertension. A hyperdynamic RV is noted over the precordial area in thin children, and it can also be appreciated by palpating a right ventricular heave at the right sternal border. Auscultation findings include a normal first heart sound (S1) and a loud pulmonary component of the second heart sound (P2) with widening of the second sound more noticeable with slower 
heart rates. In addition, there may be a RV S3 or S4 gallop and a systolic click associated with a dilated pulmonary artery. A holosystolic murmur from tricuspid regurgitation (TR) is best heard at the right lower sternal border. A systolic ejection murmur may be auscultated along the left sternal border from flow across the pulmonary valve and dilated main pulmonary artery. A high-pitched early diastolic murmur of pulmonary regurgitation may also be auscultated in the left upper sternal border. Jugular venous distention may be more prominent in older children, reflecting increased right atrial pressure. Patients with more overt signs of right heart failure will present with hepatomegaly, ascites, peripheral edema and weight loss resulting from malabsorption due to bowel edema.

\section{DIAGNOSTIC EVALUATION}

By definition, IPAH is a diagnosis of exclusion. $\mathrm{PAH}$ is the common denominator for multiple systemic disorders, and therefore a thorough evaluation to diagnose potentially treatable conditions must be performed. This should include a detailed history and physical examination, laboratory tests, noninvasive imaging and invasive hemodynamic studies. A detailed family history of pulmonary hypertension, congenital heart disease, rheumatologic disorders, other congenital anomalies, and unexplained deaths should be obtained. Recent travel to high-altitude locations, a history of anorexigenic drug use, and use of chemotherapeutic agents like dasatinib, a tyrosine kinase inhibitor which has been associated with $\mathrm{PAH}$ [53].

The recommended diagnostic work-up for children suspected of having IPAH is similar to that for adults [15]. Pre- and post-ductal pulse oximetry should be obtained when assessing an infant with $\mathrm{PAH}$, as a low post-ductal oxygen saturation could indicate the presence of a right to left ductal shunt, while a right to left atrial shunt would give low pre- and post-ductal saturations.

It is important to perform a complete diagnostic work-up to rule out all secondary causes before making a diagnosis of IPAH. A comprehensive laboratory evaluation with thoughtful clinical judgment should be made. Laboratory testing includes baseline chemistries and more specialized tests to rule out potential comorbidities in children with IPAH [15]. Pulmonary hypertension in children often presents in association with other syndromes, and they are often difficult to classify into only one Group [79]. Although Group I PAH encompasses different clinical presentations, they can share similar histopathologic changes in the pulmonary vasculature, allowing us to apply similar therapeutic approaches $[80,81]$.

Brain Natriuretic Peptide (BNP) is an important biomarker in children with IPAH, used to monitor response to therapy, progression of the disease and mortality risk $[82,83]$. BNP or B-type natriuretic peptide, is synthesized in response to volume expansion or pressure overload in the ventricular myocardium. Its precursor, pre-proBNP, is cleaved first to proBNP, then to the biologically active BNP and the inactive amino-terminal fragment (NT-proBNP). BNP and NT-proBNP levels are reasonably correlated in the clinical setting, but they are measured by different assays and their absolute numbers are not interchangeable. NT-proBNP has a longer half-life in plasma than BNP; therefore, NT-proBNP levels are generally higher than BNP and display less variability. NT-proBNP also appears to be more affected by renal function than BNP [84].

BNP and NT-proBNP levels vary according to age [85]. BNP values drop to adult levels by 2 weeks of life $(45 \mathrm{pg} / \mathrm{mL})$. In children with PAH, BNP levels $>180 \mathrm{pg} / \mathrm{mL}$ are associated with decreased survival rate [83].

Serial measurements of BNP are beneficial in predicting hemodynamic changes. BNP levels have an inverse relationship with cardiac index and a direct relationship with mean right atrial pressure (mRAP), mean pulmonary artery pressure (mPAP), pulmonary capillary wedge pressure (PCWP) and pulmonary vascular resistance (PVR) [83].

Other important diagnostic tests for the evaluation of PAH include: echocardiography, cardiac catheterization, 6-min walk test (6MWT), cardiopulmonary exercise test, 
computerized tomography, magnetic resonance and lung perfusion scan.

\section{Echocardiography}

The echocardiogram is the first line tool for the diagnosis and follow-up of patients with PAH.

Echocardiography can provide an indirect assessment of hemodynamics and both 2-D imaging and Doppler echocardiography have an important role in assessing structural abnormalities and assessing myocardial function. Right atrial pressure (RAP) is often assumed to be low, but patients with PAH often have elevated RAP. Echocardiography can provide an estimated RAP by evaluating inferior vena cava (IVC) distensibility. Long-axis interrogation of the IVC from subcostal imaging, $1-2 \mathrm{~cm}$ from the RA junction, can predict elevated RA pressures $>10 \mathrm{~mm} \mathrm{Hg}$ in PAH patients with $89 \%$ sensitivity and $76 \%$ specificity using the IVC distensibility index [86]. Right atrial size assessment from the apical four-chamber view can also be an important marker for response to therapy and outcomes in PAH.

Tricuspid regurgitant jet velocity by continuous wave Doppler is used to estimate RV systolic pressure using the modified Bernoulli equation (RVSP-RAP $=4 \mathrm{~V}^{2}$ ), where $\mathrm{V}$ is TR jet velocity, RVSP-RV the systolic pressure and RA pressure is the right atrial pressure. The RAP is usually not included in younger children as it is only $0-5 \mathrm{~mm} \mathrm{Hg}$. Technical factors like an incomplete spectral Doppler envelope can easily underestimate PASP. Furthermore, estimated PASP by Doppler can be significantly different compared to right heart catheterization (RHC) in $48 \%$ of cases [87].

Different orthogonal planes should be used to assess RV size and function. As RV hypertension worsens, RVH becomes prominent and interventricular interactions are affected. As a general rule, systolic septal flattening is consistent with half-systemic PASP and systolic posterior septal bowing into the LV is consistent with supra-systemic PASP. The RV/LV end systolic diameter ratio can also assess septal shift secondary to elevated RV pressure, with a RV/LV ratio of $>1$ being associated with increased risk for adverse events in children with PAH [88]. Other methods to assess RV function are tricuspid annular plane systolic excursion (TAPSE), myocardial performance index (MPI) and strain imaging. TAPSE in children varies according to age, and is an important marker of RV longitudinal systolic function that can correlate with response to therapy. Patients with severe or longstanding $\mathrm{PAH}$ can also show abnormal mitral and tricuspid inflow velocities, reflecting diastolic dysfunction. Tissue Doppler imaging can be abnormal in PAH and reflects diastolic dysfunction [87]. Fractional area change (FAC) is a surrogate of RV ejection fraction; however, good-quality imaging of the $\mathrm{RV}$ free wall is often difficult to obtain in older children $[89,90]$. When pulmonary regurgitation (PR) is present, the mPAP can be estimated by measuring the peak velocity of the PR jet.

Pulmonary vascular resistance (PVR) can be estimated by measuring the peak TR velocity and the ratio between RVOT (right ventricular outflow tract) and VTI (velocity time integral), which has been validated against RHC [87, 91, 92]. Another novel method that correlates with invasive hemodynamics is right ventricle stroke work (RVSW), which can be predictive of outcomes in children with $\mathrm{PAH}$ [93].

\section{Cardiac Catheterization}

Right heart catheterization is the "gold standard" for diagnosis, evaluation of severity and prognosis in $\mathrm{PAH}$.

Diagnostic catheterization should include acute vasodilator testing (AVT) with 20-80 parts per million (ppm) of iNO. There are several definitions for acute vasodilatory response. Barst et al. defined acute vasodilatory response as a reduction in mean PA pressure and PVR of $20 \%$, with no change or increase in cardiac output and a decreased or unchanged pulmonary to systemic vascular resistance (Rp/Rs) ratio [94]. Sitbon et al. defined response to AVT as a drop in mean PAP by $>10 \mathrm{~mm} \mathrm{Hg}$ to $<40 \mathrm{~mm} \mathrm{Hg}$, and an increased or unchanged cardiac output. The Sitbon criteria has shown superiority in identifying patients with 
improved survival who will benefit from calcium channel blockers therapy; however, it may be difficult to use in younger children with overall lower systemic and pulmonary pressures [95]. A lower mPAP/mSAP and lower Rp/Rs ratio is considered a better prognostic index in children. Calcium channel blockers (CCBs) are indicated in patients who are AVT responders. Acute responders have less severe disease, as demonstrated by a higher proportion of patients in NYHA functional class I or II $(47 \%$ compared with $15 \%$ in nonresponders), a better 6MWT, lower PVR and higher survival. Those who do not manifest a response to AVT are unlikely to benefit from chronic oral CCBs, and CCBs are contraindicated in them [15, 95-97]. Cardiac catheterization is overall a safe procedure when performed at centers with expertise in the care of PAH patients, with low complication rates $(5.7 \%)$ and very low mortality $(0.2 \%)$ [98].

\section{Cardiopulmonary Exercise Testing (CPET)}

Children with pulmonary arterial hypertension often have an exaggerated response of the pulmonary vascular bed to exercise and to hypoxia as compared with adults [99].

Children with IPAH have significant impairment of aerobic capacity with significantly lower peak oxygen consumption $\left(\mathrm{VO}_{2}\right)$. Heart rate, rhythm, oxygen saturation and blood pressure are routinely recorded during CPET. CPET is used to evaluate and follow-up children with PAH. It is usually possible in children over 7 years of age using a bicycle ergometer or a treadmill in taller children [100].

\section{Six-Minute Walk Test (6MWT)}

The 6MWT is a valuable and easy to perform test in children with PAH. It records heart rate and oxygen saturation at baseline and after walking for $6 \mathrm{~min}$ in a safe environment. Distance walked and symptoms at the end of the $6 \mathrm{~min}$ are recorded. 6MWDT is most helpful when done serially to assess response to therapy. The $6 \mathrm{MWT}$ was able to accurately predict peak oxygen consumption in children with
IPAH [101]. It is useful to assess functional capacity and correlates with outcome in adults, but it has not been standardized in children with PAH [102].

\section{Magnetic Resonance Imaging (MRI)}

Although echocardiography is widely available, MRI has become the gold standard for the quantification of RV volume and RV function. $\mathrm{RV}$ function is the main predictor of survival in PAH patients. Cardiac MRI parameters such as RV ejection fraction (RVEF) and left ventricular stroke volume indexed (LVSVi) have been associated with increased risk of death or transplantation. Unfortunately, MRI often requires longer scanning times and the use of sedation or general anesthesia in children, conditions which are not ideal in patients with severe $\mathrm{PAH}$ who need close and continuous monitoring [103-105].

\section{Computerized Tomography (CT)}

CT scanning time is shorter than MRI, and is more readily available in most centers. A high resolution CT can be considered when assessing $\mathrm{PAH}$ in children, to rule out lung parenchymal disorders including interstitial lung disease and PVOD. CT angiography can detect pulmonary venous stenosis, vascular malformations or the presence of pulmonary thromboembolic disease. CT can be complementary to cardiac catheterization, and in some instances it could outline vascular anatomy with less radiation exposure. One must always be conscious of the stochastic effects of ionizing radiation. Children with chronic illnesses such as $\mathrm{PAH}$, chronic lung disease and congenital heart disease are often exposed to multiple X-rays throughout their lives. The cumulative radiation dose to which children are exposed is directly associated with a higher risk of cancer, especially in younger children whose tissues are more radiosensitive compared to adults. The ALARA (as low as reasonably possible) principle should always be the goal when performing CT in children with PAH [15, 106-109]. 


\section{Ventilation/Perfusion Scan (V/Q Scan)}

V/Q Scan is used to assess ventilation-perfusion mismatch from airway or vascular obstruction, and is most useful in the presence of pulmonary embolism. V/Q Scans are challenging in children as they require that a child be still for several minutes after the inhalation of a radioisotope and the injection of radioisotope-tagged albumin, often requiring sedation or anesthesia [15]. Although Group $4 \mathrm{PH}$ is not seen as often in children compared to adults, thrombophilic disorders such as Protein $\mathrm{C}$ and Protein $S$ deficiency can present early in life or in genetically predisposed teenage girls taking estrogen containing contraceptives being at risk for chronic pulmonary thromboembolic events [110-113].

\section{Other Testing}

Polysomnography may be necessary to assess for episodes of hypoxia and whether these episodes are predominantly obstructive, central, or from mixed causes. A sleep study is also indicated when patients show poor responsiveness to PAH treatment. Pulmonary function testing should be considered to asses for reversible lung disease or airway abnormalities as well as for follow-up evaluation [15].

\section{BIOMARKERS}

Novel biomarkers are being developed as we continue to unveil the physiopathology of PAH. The goal is to discover less invasive, sensitive and accurate tests that can screen, diagnose and correlate clinically in patients with PAH [114]. The analysis of biomarkers associated with oxidative stress and also multiple metabolites, including carbohydrates, lipids, nucleotides, amino acids and amines, can become crucial for a more comprehensive evaluation of $\mathrm{PAH}$ [115-117]. Non-protein biomarkers like micro-RNAs are associated with gene expression in pulmonary vascular diseases. Other biomarkers of endothelial damage are circulating endothelial cells (CEC) and circulating progenitor cells
(CPC). CEC and CPC counts are elevated in patients with $\mathrm{PAH}$ and may provide an estimate of individual vascular competence that results from the equilibrium between injury and repair mechanisms, and may yield prognostic clues in vascular diseases [118]. Future application of biomarkers in children will likely offer new understanding into the disease mechanisms of $\mathrm{PAH}$ in children [13].

\section{TREATMENT}

Several advances have been made in the last two decades for the treatment of IPAH. Currently, there are 14 medications that have been approved in adults for PAH. All PAH-specific medications are used off-label in children. Since the discovery of epoprostenol in the 1970s and Food and Drug Administration (FDA) approval for intravenous (IV) use in 1995, there has been an important increase in survival rates in patients with various types of PAH [3, 7, 15, 99]. Further research is still needed to assess the benefit of all these medications in children.

\section{General Treatment Measures}

The primary care provider (PCP) plays an invaluable role in the care of children with $\mathrm{PAH}$. All children with PAH presenting with fever, respiratory infection and cardiac symptoms require prompt evaluation. Children often have a more reactive pulmonary vascular bed compared to adults, and when not evaluated and treated aggressively, alveolar hypoxia and sudden increase in pulmonary pressures can result in a $\mathrm{PH}$ crisis.

Infants who are at risk for hospitalization due to respiratory syncytial virus (RSV) infections should follow the American Academy of Pediatrics guideline recommendations for primary prevention [119]. Annual influenza and pneumococcal vaccination are also recommended [15]. Antipyretics should be administered for temperature elevations greater than $38^{\circ} \mathrm{C}\left(100.4^{\circ} \mathrm{F}\right)$ to minimize the consequences of increased metabolic demands on an already compromised cardio-respiratory system. 
Antitussive medications are also important in children with $\mathrm{PAH}$, as cough can increase intrathoracic pressure, decreasing systemic venous return and cardiac output leading to syncope; this has been described as vasovagal insufficiency in patients with PAH [120]. Antitussive medications are also important in children with $\mathrm{PH}$ after episodes of hemoptysis, to prevent further bleeding. Decongestants such as pseudoephedrine which are commonly found in over-the-counter combinations should be avoided as they may exacerbate the pulmonary hypertension [121]. Constipation is also a common problem in the pediatric population, and it should be addressed promptly in patients with PAH as Valsalva maneuvers can precipitate syncopal episodes.

\section{Anticoagulation}

More than half of the autopsy specimens of patients with IPAH show thrombi as a major histologic feature. Consideration of chronic anticoagulation in children with $\mathrm{PAH}$ is based on studies in adults with IPAH. Warfarin has been shown to be associated with improved survival in adult patients [120]. Warfarin may be considered in children with IPAH, patients with low cardiac output, those with a long-term indwelling catheter and those with hypercoagulable states. The target goal international normalized ratio (INR) for children with $\mathrm{PAH}$ is between 1.5 and 2.0. Medication interactions should also be taken into consideration when patients are taking warfarin. Whether chronic anticoagulation is efficacious as well as safe for children with PAH remains to be determined [15].

\section{Inhaled Nitric Oxide (iNO)}

Nitric oxide is used for AVT during right heart catheterization, and for treating acute PAH crisis in IPAH patients as well as following cardiac surgery. iNO is the first choice therapy in mechanically ventilated patients and can be considered early as it has less impact on SVR compared to systemic pulmonary vasodilators [122]. iNO enhances ventilation-perfusion matching, increasing blood flow to well-ventilated lung areas, compared to systemic vasodilators which produce vasodilation in areas of non-ventilated lung. Formation of nitrogen dioxide $\left(\mathrm{NO}_{2}\right)$ is dependent on iNO concentration, with minimal production at $20 \mathrm{ppm}$ of iNO. The most common adverse effect is pulmonary edema from high concentrations of $\mathrm{NO}_{2}$ and methemoglobinemia, which is also uncommon in patients breathing $\mathrm{NO}$ at doses $\leq 80 \mathrm{ppm}$ [123].

\section{ADDITIONAL PHARMACOTHERAPY}

Supplemental oxygen is reasonable to avoid episodic or sustained hypoxemia with a target oxygen saturation of $92-95 \%$ to prevent adverse effects of hypoxia. Children with $\mathrm{PAH}$ may require oxygen during sleep, during physical activities for intracardiac shunting or during flights. The use of supplemental oxygen during airplane travel is reasonable, as most commercial aircrafts are pressurized at 6000-8000 feet (c. 1830-2440 m) above sea level, which could lead to hypoxemia and subsequent elevation of PAP $[15,124]$.

Prompt detection and management of arrhythmias is essential as they can precipitate an abrupt decrease in cardiac output and clinical deterioration. Signs or symptoms of volume overload can be managed with diuretics. Children with decreased RV systolic function with clinical signs of failure may benefit from digitalis (digoxin) $5 \mathrm{mcg} / \mathrm{kg}$ orally twice daily up to 10 years of age, then $5 \mathrm{mcg} / \mathrm{kg}$ once daily with a maximum dose of $125 \mathrm{mcg}$ per day. [15].

\section{TARGETED THERAPY}

The main goals of therapy in $\mathrm{PAH}$ are to improve quality of life, improve hemodynamics, halt the progression of disease and increase life expectancy. Risk stratification for children with PAH is important. Treatment goals may be divided into those patients who are at lower or higher risk for death. In adults, clinical evidence of RV failure, worsening symptoms and elevated BNP levels are associated with a higher risk of 
death. WHO-FC III-IV and failure to thrive in children with $\mathrm{PAH}$ have been associated with higher risk of death. Additional high-risk factors include severe RV enlargement with decreased ventricular function, pericardial effusion, mean pulmonary artery pressure and mean systolic arterial pressure $(\mathrm{mPAP} / \mathrm{mSAP})$ ratio $>0.75$, right atrial pressure (RAP) $>10 \mathrm{mmHg}$ and PVRi $>20 \mathrm{wu} / \mathrm{m} 2$. A treatment algorithm was presented by the Pediatric Task Force of the 5th World Symposium on Pulmonary Hypertension (WSPH) in Nice, France (2013) [125]. (Fig. 2) Targeted PH therapy is recommended based on AVT and risk stratification of each patient. There are four main groups of medications that included calcium channel blockers, prostaglandin analogues, endotheling receptor antagonis and PDE-5 inhibitors.

\section{Calcium channel blockers (CCBs)}

CCBs are recommended in children who demonstrate a robust response to AVT. A significantly greater percentage of children than adults are acute responders (40 vs. $20 \%$ ). Survival rates of children with IPAH at 1,5 , and 10 years were 97,97 , and $81 \%$, respectively. for acute responders (AR) on high-dose CCBs. Most studies have used relatively high doses, e.g., long-acting nifedipine $120-240 \mathrm{mg}$ daily or amlodipine $20-40 \mathrm{mg}$ daily; however, the optimal dosing for children with IPAH is uncertain. The pediatric guidelines recommend nifedipine at a starting dose of $0.1-0.2 \mathrm{mg} / \mathrm{kg}$ orally three times daily (TID), titrated to a dose range of $2-3 \mathrm{mg} / \mathrm{kg} /$ day; diltiazem, starting dose $0.5 \mathrm{mg} /$ $\mathrm{kg}$ orally TID, titrated to a dose range of $3-5 \mathrm{mg} /$ $\mathrm{kg} /$ day; and amlodipine, starting dose $0.1-0.3 \mathrm{mg} / \mathrm{kg}$ orally once daily, up to 2.5-7.5 mg orally once a day. Follow-up AVT is important to determine responsiveness. Yung et al., reported that close to half of the patients who were responsive at initial catheterization became unresponsive over a 10-year follow-up period, increasing the risk of treatment failure on CCB $[4,15,16,97]$.

\section{Prostaglandins}

Recognizing the effect of prostacyclin as a pulmonary vasodilator has revolutionized therapy for PAH, modifying the natural history of IPAH. With the introduction of epoprostenol in the post-prostanoid era, there have been major improvements in life expectancy and quality of life in both adults and children. Epoprostenol
Fig. 2 Treatment algorithm in the management of children with PAH. World symposium on pulmonary hypertension 2013 consensus pediatric IPAH/FPAH treatment algorithm. $C C B$ calcium channel blocker, ERA endothelin receptor antagonist, $I V$ intravenous, $P D E-5 i$ phosphodiesterase 5 inhibitor, $S Q$ subcutaneous. Adapted from [125]

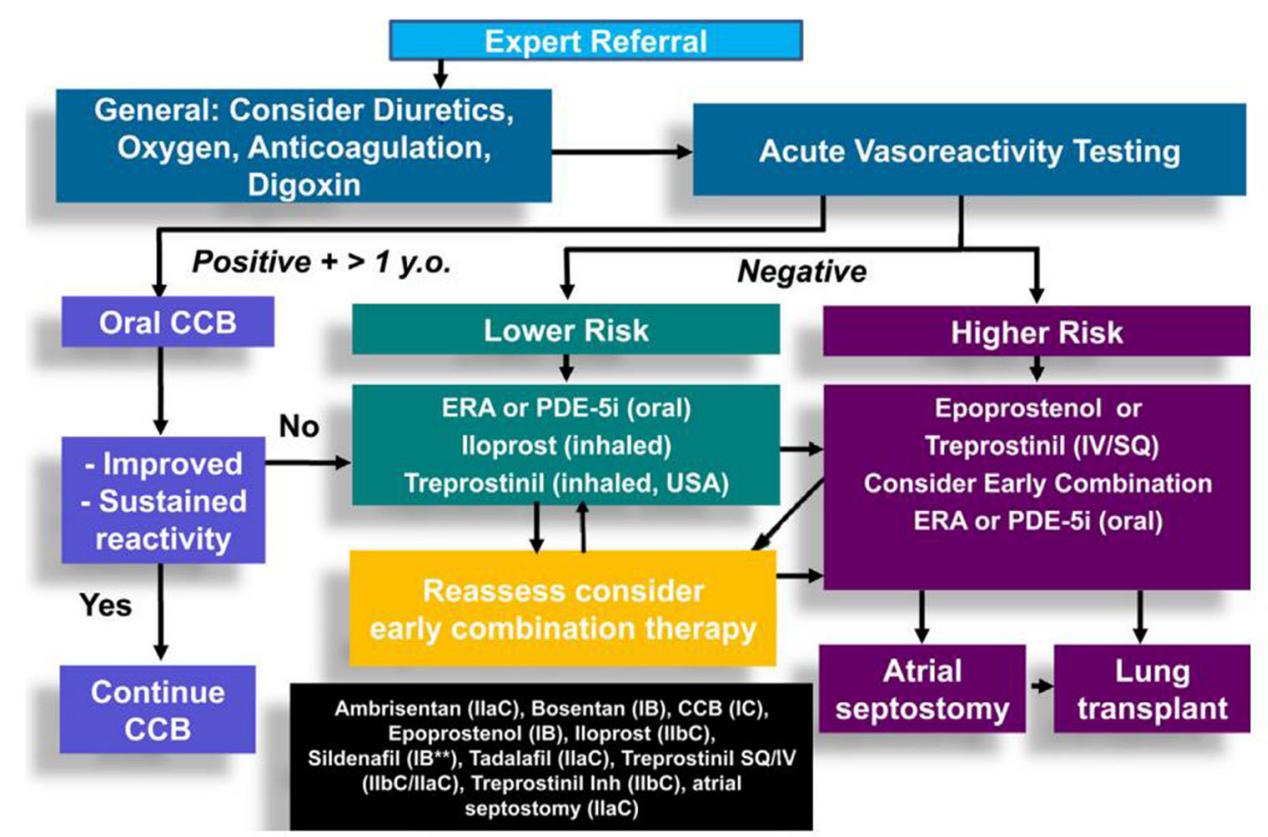


has been shown to improve hemodynamics, quality of life, and exercise capacity in patients with PAH. Chronic intravenous epoprostenol lowers pulmonary artery pressure, increases cardiac output, increases oxygen transport, and improves exercise capacity, hemodynamics, and survival in patients with IPAH [7, 97, 99, 126].

Epoprostenol (PGI2) is a potent vasodilator of all vascular beds with proven efficacy in patients with New York Heart Association (NYHA) Class III or IV with IPAH. It is FDA-approved for patients above 18 years of age with IPAH. Epoprostenol is a potent endogenous inhibitor of platelet aggregation. It is administered by continuous intravenous (IV) infusion through a central line due to its very short half-life of $\sim 6 \mathrm{~min}$. Peripheral lines can be used temporarily until central line is established. There are two commercially available formulations of epoprostenol. Epoprostenol is a more thermo-sensitive solution and requires to be stored at $2-8{ }^{\circ} \mathrm{C}$ before use; once reconstituted is only stable for $8 \mathrm{~h}$ on room temperature $\left(15-25^{\circ} \mathrm{C}\right)$, and therefore patients require to use cold packs to keep the solution stable for $24 \mathrm{~h}$. A newer thermostable formulation is now available, which can be stored and infused at room temperature $\left(20-25^{\circ} \mathrm{C}\right)$, but still needs to be protected from light. Patients are educated to prepare their daily formulation at home. Response to initial therapy is evaluated in a hospital setting to monitor hemodynamic effects, before chronic therapy is administered. The initial dose is $1-2 \mathrm{ng} / \mathrm{kg} / \mathrm{min}$, titrated up to a goal dose or dose-limiting side effects are observed. The usual goal dose is between 50 and $80 \mathrm{ng} / \mathrm{kg} / \mathrm{min}$, reached within the first few months. There is no maximum dose in children, with some patients showing a proportional dose-related response requiring doses $>100 \mathrm{ng} / \mathrm{kg} / \mathrm{min}$. Some of the most common adverse effects of PGI2 are flushing, jaw pain, foot and bone pain, headaches and diarrhea, which are often well tolerated by children when present. Meticulous care of the central line is necessary to prevent associated complications such as site and line infection, line thrombosis, line occlusion and need for replacement. Pump malfunction is another potential problem that can lead to interruption of medication delivery, and could lead to acute hemodynamic decompensation. Therefore, a search for alternate routes of drug delivery has led to the clinical investigation of oral, inhaled, subcutaneous and more stable and longer-acting intravenous prostacyclin analogues $[7,15,126]$.

Treprostinil is a longer-acting prostacyclin analogue. It was initially approved by the FDA in 2002 for parenteral use. Since then, newer inhaled and oral formulations have been approved for adults. The elimination half-life is $4.5 \mathrm{~h}$, becoming a medication with a higher safety profile compared to epoprostenol, but abrupt withdrawal may also lead to rebound pulmonary hypertension. The starting dose is $1-2 \mathrm{ng} / \mathrm{kg} / \mathrm{min}$, and a stable goal dose is usually between 50 and $80 \mathrm{ng} / \mathrm{kg} / \mathrm{min}$ according to the pediatric guidelines. In practice, the treprostinil dose is usually 1.5-2 times higher compared to epoprostenol. Flushing, muscle pain, headaches, and diarrhea are also common side effects, but less frequent compared to epoprostenol. Subcutaneous treprostinil has equivalent pharmacokinetics to intravenous and is an attractive option because of ease of administration not needing an indwelling intravenous catheter. One of the most common adverse effects is discomfort at the administration site, which is less frequent in children compared to adults [127, 128].

Inhaled treprostinil was approved in 2010 for adults with PAH. Four times a day administration is recommended, often as part of combination therapy with PDE5 inhibitor and/or ET-1 receptor blocker. The goal dose is nine breaths (54 ng) per treatment, four times a day. Inhaled treprostinil is well tolerated in children with IPAH, showing improvement in WHO functional class, $6 \mathrm{MWD}$ and peak $\mathrm{VO}_{2}$. Some children may have worsening of reactive airway symptoms [15, 129]. Oral treprostinil was approved in 2002 in extended release tablets, and maximum dose is determined by tolerability. Some adult patients with stable symptoms and hemodynamics (WHO FC I or II with baseline cardiac index $>2.2 \mathrm{~L} / \mathrm{min} / \mathrm{m}^{2}$ ) on parenteral treprostinil could be transitioned to oral treprostinil, a more convenient twice a day dosing. There is limited experience in children [130]. 
Inhaled iloprost, a synthetic analogue of prostacyclin, is an alternative in the acute setting. It can be delivered rapidly and has less systemic adverse effects compared to IV prostacyclin. It has also been used to assess pulmonary vasoreactivity in children with PAH. Iloprost has a short half-life of 20-30 min, thus frequent administration is needed (6-9 inhalations per day). The addition of inhaled iloprost therapy can reduce the need for IV prostanoid therapy in some patients. Inhaled iloprost can trigger reactive airway disease symptoms, which could also limit or affect drug delivery to the lower airway $[15,131]$.

Beraprost sodium, is an oral prostacyclin analogue, whose potency is approximately 50\% that of epoprostenol. Initial studies showed a good safety profile with improvement of functional capacity and symptoms, but long-term use at 12 months failed to show improvement in exercise capacity assessed by 6MWT. It is not approved for use in the United States [132, 133].

More recently, the oral prostacyclin receptor (IP) agonist selexipag was FDA approved for the management of adults with PAH. The density of IP receptors varies among patients, with some patients responding to low, medium or high doses (up to 1600 mcg twice daily). Dose titration can be limited by side effects such as headaches, diarrhea, nausea and jaw pain that could lead to therapy discontinuation [134].

\section{Endothelin receptor antagonists (ERA)}

There are only oral formulations of ERA. Bosentan is an oral nonselective ERA. It is well tolerated and effective in children with PAH. Bosentan has shown to improve WHO FC and survival in children with PAH [135]. Bosentan serum concentration peaks $3-5 \mathrm{~h}$ after each dose, with a terminal half-life of about $5 \mathrm{~h}$. Bosentan dose varies according to weight. For children $<10 \mathrm{~kg}$, $2 \mathrm{mg} / \mathrm{kg}$ twice daily is recommended; for children $10-20 \mathrm{~kg}, 31.25 \mathrm{mg}$ twice daily is recommended; for children $>20-40 \mathrm{~kg}, 62.5 \mathrm{mg}$ twice daily is recommended; and for children $>40 \mathrm{kgm}$ $125 \mathrm{mg}$ twice daily is recommended. Bosentan has a US Black Box Warning regarding hepatotoxicity and teratogenicity. It is associated with transaminase elevations (ALT or AST $\geq 3$ times upper limit of normal) and increased bilirubin level. Monthly liver function tests (LFTs) are required or at least every 2 weeks if LFTs are elevated. Treatment should be stopped with any clinical symptoms of hepatic injury or a serum bilirubin $\geq 2$ times the upper limit of normal, while safety of reintroduction is unknown [15, 133, 135-137].

Ambrisentan is a once a day selective $\mathrm{ET}_{\mathrm{A}}$ receptor blocker. It has a terminal half-life of $\sim 15 \mathrm{~h}$. Children with PAH can be started at $2.5 \mathrm{mg}(<20 \mathrm{~kg})$ or $5 \mathrm{mg}$ dose $(\geq 20 \mathrm{~kg})$ and considered for an up-titration to the $5-10 \mathrm{mg}$ dose. Ambrisentan has an acceptable safety profile with less risk of hepatotoxicity. Routine LFTs are recommended in children at baseline and at periodic intervals. The most common side effects are nasal congestion and headaches. Ambrisentan has shown improvement of WHO-FC and hemodynamics in children with $\mathrm{PAH}$, and some children can be safely switched from bosentan to ambrisentan [138].

Macitentan is the newest oral endothelin receptor blocker approved for adults with PAH in October 2013. A single daily dose of $10 \mathrm{mg}$ is recommended for adults. This dose was shown to reduce morbidity and mortality in patients with PAH compared to placebo and a lower daily dose of $3 \mathrm{mg}$ [139]. Clinical trials are currently underway in children. Special education for females who are taking ERA is required due to its potential teratogenic effects. Pregnancy must be excluded prior to starting therapy, monthly throughout treatment and for 1 month after stopping ERA.

\section{Phosphodiesterase 5 (PDE5) inhibitors}

Sildenafil, a PDE5 inhibitor, is one of the frontline medications for the treatment of IPAH in children. Of historical importance, sildenafil was approved by the FDA in June 2005 for the treatment of adults with PAH. Subsequently, the European Medicines Agency (EMA) approved sildenafil for the treatment of pediatric patients aged 1-17 years old with PAH in May 2011. In August 2012, the FDA issued a warning against the chronic use of sildenafil in children (ages 
1-17 years) with PAH based on the STARTS trial results. The STARTS-I and II trial is a large randomized, double-blind placebo-controlled study of sildenafil as monotherapy. Patients were randomized to placebo and low-, medium- and high-dose sildenafil. After 3 years of follow-up, $20 \%$ of IPAH patients in the high-dose group died compared to $9 \%$ and $14 \%$ in the low- and medium-dose groups, respectively. The higher mortality reported in the high-dose group led to the FDA warning. After further discussion with experts in the field of pediatric PAH (PPHNET), and more careful analysis of the results of the STARTS trial, in March 2014, the FDA issued a clarification statement, recognizing that there may be situations in which the risk-benefit profile of sildenafil may be acceptable in individual children, and the medication should be administered by experienced physicians, at low doses similar to the EMA in Europe [140].

Recommended doses are based on the results of the STARTS- 1 and STARTS- 2 trials. The recommended dose for children $<1$ year of age is $0.5-1 \mathrm{mg} / \mathrm{kg}$ orally three times a day; for weight $<20 \mathrm{~kg}, 10 \mathrm{mg}$ orally three times a day; and for weight $>20 \mathrm{~kg}, 20 \mathrm{mg}$ orally three times a day. Sildenafil serum levels peak at $1-2 \mathrm{~h}$ after oral dose, which is important to know to monitor for adverse effects such as hypotension, flushing, nasal congestion, priapism and agitation. Sildenafil is particularly beneficial in post-operative patients in preventing rebound $\mathrm{PH}$ at the time of iNO withdrawal [141-145].

Tadalafil is a PDE5 inhibitor with similar pharmacologic effects as sildenafil. Tadalafil has a longer half-life of 15-17.5 h, allowing once a day dosing. The starting dose is $0.5-1 \mathrm{mg} /$ $\mathrm{kg} / \mathrm{day}$, with a maximum dose of $40 \mathrm{mg}$ orally daily. Children can be safely switched to tadalafil from sildenafil, maintaining the clinical effects of sildenafil $[15,129]$.

\section{Combination Therapies}

The approach to initiation of targeted therapy in children with PAH is determined by the severity of the disease and the symptomatic burden. Adult trials, such as AMBITION, BREATH-2, GRIPHON, SERAPHIN, COMPASS-2, have looked at the benefits of using drug combination therapies in $\mathrm{PAH}$, looking at different end-points such as WHO-FC and catheterization data. The rationale for upfront combination therapy is to aggressively tackle different pathways involved in the physiopathology of PAH and to attempt to halt disease progression [134, 146, 147]. Patients who are treated with dual or triple therapy tend to have a higher WHO-FC and PVRi at diagnosis than those treated with monotherapy. Initiation of prostacyclin therapy has been and remains the cornerstone of management for patients with WHO-FC IV. For most patients who are WHO-FC II or III at the time of diagnosis, oral agents such as a PDE5 inhibitor or ERA are usually recommended [47, 134, 147-150].

\section{NOVEL THERAPIES IN PAH}

Recent research is focusing on reversing the molecular triggers that are unique to the RV and promote decompensation at a much earlier stage than in the LV. There is a metabolic decompensation with progressive RVH and increased RV afterload, possibly driven by mitochondrial dysfunction and molecular signaling pathways that can be targeted early and lead away from RV failure. Patients with RVH have a higher expression of PDE-5 compared to patients with normal RV myocardial cells; this is thought to cause a direct positive inotropic effect in the RV, likely due to cross-talk with the PDE-3 pathway. Inflammation also plays an important role in the pathogenesis of PAH. There is inhibition of regulatory T-cells, higher circulating interleukins and growth factors that have been correlated with worse prognosis in patients with $\mathrm{PAH}$. Cyclosporine, which inhibits the production and release of IL-2, has been shown to cause regression of the degree of pulmonary artery remodeling, pulmonary artery pressures, and RVH in animal models. Etanercept, a potent anti-inflammatory agent and TNF- $\alpha$ inhibitor, reversed vascular remodeling and improved hemodynamics in preclinical models of PAH. Survivin is an inhibitor of apoptosis and is highly expressed in most cancers by growth factor signaling from PDGF and EGF; in vivo models have shown reversal of the disease in PAH [151]. 
Tacrolimus (FK506) is a potent immunosuppressant that also potentiates the bone morphogenic protein signaling pathway in pulmonary arterial endothelial cells, promoting vessel regeneration in PAH [152, 153].

The RhoA/Rho-kinase pathway plays an important role in various fundamental cellular functions, including contraction, motility, proliferation, and apoptosis, leading to the development of cardiovascular disease. Rho-kinase activity is significantly increased in the $\mathrm{PH}$ patients overall compared with controls. Fasudil, a Rho-kinase inhibitor, inhibits vascular smooth muscle cell contraction of pulmonary arteries improving hemodynamics in IPAH patients [154-156].

\section{Pulmonary Artery Denervation (PADN)}

PADN is a transcatheter procedure that can be performed in patients with $\mathrm{PAH}$ who do not respond to maximal medical therapy. Increased neurohumoral activation in PAH leads to increased circulating catecholamine levels, abnormally high muscle sympathetic nerve activity, and impaired heart rate variability, which forms the theoretical basis of using PADN. In an adult cohort of 66 patients, 56 patients at 1 year follow-up showed improvement in mean PAP, cardiac output and PVR $[157,158]$.

\section{Blade-balloon Atrial Septostomy (BAS)}

Atrial septostomy should be considered as a palliative measurement in children with $\mathrm{PAH}$ who present with recurrent syncope, chest pain or severe RV failure despite maximal medical therapy. Atrial septostomy is thought to protect against syncope by allowing right to left shunting at the atrial level, maintaining cardiac output, particularly during a $\mathrm{PH}$ crisis. Patients with mean right atrial pressure $>20 \mathrm{mmHg}$ and with systemic arterial saturation $<90 \%$ should be carefully assessed, since BAS could lead to massive atrial shunting and severe systemic desaturation. BAS has also been described as a safe palliative procedure as a bridge to recovery or to lung transplantation [159-161].

\section{Potts Shunt (PS)}

PS is a palliative procedure done in patients with supra-systemic RV pressures. It entails creating a shunt between the left pulmonary artery and the descending thoracic aorta, avoiding brain and coronary hypoxia. PS should be considered early in the clinical course, before RV function progressively declines. PS decreases $\mathrm{RV}$ afterload, improving interventricular interactions, LV ejection fraction and ultimately improving functional class. This can be considered as an alternative or as a bridge to lung transplantation [162, 163].

\section{Mechanical Support and Lung Transplantation}

Patients with PAH who present with hemodynamic collapse might be candidates for cardio-respiratory mechanical support. Right ventricular assist device and ECMO have been implemented in $\mathrm{PH}$ patients as a bridge to recovery or as a bridge to transplant [164].

IPAH is the second most common indication for pediatric lung transplantation (LTx), which comprises $\sim 9 \%$ of all transplanted patients, most commonly in children aged 1-5 and $6-10$ years. The observed survival in children is similar to that of adult lung transplantation. The median survival for infants and children up to 10 years is $6-6.7$ years; children $11-17$ years of age, have a lower survival at 4.6 years. Low survival is usually related to chronic allograft rejection. These children also encounter other co-morbidities related to LTx such as hypertension, renal dysfunction, hyperlipidemia, and diabetes mellitus. Although pediatric LTx can be considered as an option, there are very few established pediatric LTx programs in the United States. Further research is needed to improve outcomes and quality of life in this population [165].

\section{Pregnancy and PAH}

Age-appropriate counseling to female teenagers and parents of patients with $\mathrm{PH}$ should be carried out regarding the effects of pregnancy and 
teratogenic effects of some PH medications [15]. The hemodynamic and hormonal changes that occur during pregnancy pose a higher risk of mortality for patients with PAH. Maternal death has been reported in $30 \%$ of women with IPAH and up to $56 \%$ in women with secondary $\mathrm{PH}$. There are very few cases of women with IPAH and successful pregnancy. Those who carried out the pregnancy and survived had preterm deliveries in half of the cases. These patients also required prolonged hospitalization before and after delivery, with some of them requiring cardiorespiratory mechanical support [166-169].

\section{CONCLUSION}

Despite the multiple advances in pediatric $\mathrm{PAH}$ within the last two decades, much work is needed to continue to improve long-term survival in children. Results of targeted combination therapeutic approaches are encouraging but additional efforts toward preventing and elucidating the complex mechanisms of $\mathrm{PH}$ in the different group classifications are still necessary. Bringing PAH awareness to the community and to health-care providers is also essential, providing the tools for early diagnosis and prompt evaluation and referral of children to pediatric $\mathrm{PH}$ centers for appropriate management to improve overall quality of life.

\section{ACKNOWLEDGEMENTS}

In this report, the authors discuss several medications and therapies which are not FDA-approved for pediatric use, and use of these medications for pediatric patients is to be done only at centers with experience and expertise for caring for these patients. No funding or sponsorship was received for this study or publication of this article. All named authors meet the International Committee of Medical Journal Editors (ICMJE) criteria for authorship for this manuscript, take responsibility for the integrity of the work as a whole, and have given final approval for the version to be published.
Disclosures. Dr. Valencia has nothing to disclose. Dr. Krishnan is a Co-investigator for clinical trials at New York-Presbyterian/Columbia University Medical Center, and the University has received grant support from Actelion, Gilead, GSK and United Therapeutics with no financial support for Dr. Krishnan. Dr. Krishnan has received consulting fees from Actelion for serving on an advisory board.

Compliance with Ethics Guidelines. This article is based on previously conducted studies and does not involve any new studies of human or animal subjects performed by any of the authors.

Open Access. This article is distributed under the terms of the Creative Commons Attribution-NonCommercial 4.0 International License (http://creativecommons.org/licenses/ by-nc/4.0/), which permits any noncommercial use, distribution, and reproduction in any medium, provided you give appropriate credit to the original author(s) and the source, provide a link to the Creative Commons license, and indicate if changes were made.

\section{REFERENCES}

1. Hopper RK, Abman SH, Ivy DD. Persistent challenges in pediatric pulmonary hypertension. Chest. 2016;150(1):226-36.

2. Mullen MP, et al. Quality of life and parental adjustment in pediatric pulmonary hypertension. Chest. 2014;145(2):237-44.

3. Ivy D. Advances in pediatric pulmonary arterial hypertension. Curr Opin Cardiol. 2012;27(2):70-81.

4. Berger RM, et al. Clinical features of paediatric pulmonary hypertension: a registry study. Lancet. 2012;379(9815):537-46.

5. Barst RJ, et al. Survival in childhood pulmonary arterial hypertension: insights from the registry to evaluate early and long-term pulmonary arterial hypertension disease management. Circulation. 2012;125(1):113-22.

6. Ivy D. Pulmonary hypertension in children. Cardiol Clin. 2016;34(3):451-72. 
7. Barst R. How has epoprostenol changed the outcome for patients with pulmonary arterial hypertension? Int J Clin Pract Suppl. 2010;168:23-32.

8. Strauss WL, Edelman JD. Prostanoid therapy for pulmonary arterial hypertension. Clin Chest Med. 2007;28(1):127-42.

9. D'Alonzo GE, et al. Survival in patients with primary pulmonary hypertension. Results from a national prospective registry. Ann Intern Med. 1991;115(5):343-9.

10. Barst RJ, et al. Four- and seven-year outcomes of patients with congenital heart disease-associated pulmonary arterial hypertension (from the REVEAL Registry). Am J Cardiol. 2014;113(1):147-55.

11. Hopkins WE, et al. Comparison of the hemodynamics and survival of adults with severe primary pulmonary hypertension or Eisenmenger syndrome. J Heart Lung Transplant. 1996;15(1 Pt 1):100-5.

12. Hopkins WE. The remarkable right ventricle of patients with Eisenmenger syndrome. Coron Artery Dis. $2005 ; 16(1): 19-25$.

13. Colvin KL, Yeager ME. Proteomics of pulmonary hypertension: could personalized profiles lead to personalized medicine? Proteomics Clin Appl. 2015;9(1-2):111-20.

14. Mathew R. Pulmonary hypertension: current therapy and future prospects. Cardiovasc Hematol Agents Med Chem. 2011;9(3):165-82.

15. Abman $\mathrm{SH}$, et al. Pediatric pulmonary hypertension: guidelines from the American Heart Association and American Thoracic Society. Circulation. 2015;132(21):2037-99.

16. Douwes JM, et al. Acute pulmonary vasodilator response in paediatric and adult pulmonary arterial hypertension: occurrence and prognostic value when comparing three response criteria. Eur Heart J. 2011;32(24):3137-46.

17. Simonneau G, et al. Updated clinical classification of pulmonary hypertension. J Am Coll Cardiol. 2013;62(25 Suppl):D34-41.

18. Saji T. Update on pediatric pulmonary arterial hypertension. Differences and similarities to adult disease. Circ J. 2013;77(11):2639-50.

19. Ntiloudi D, et al. Adult congenital heart disease: a paradigm of epidemiological change. Int J Cardiol. 2016;218:269-74.

20. Krieger EV, Leary PJ, Opotowsky AR. Pulmonary hypertension in congenital heart disease: beyond
Eisenmenger syndrome. Cardiol Clin. 2015;33(4):599-609.

21. Dresdale DT, Michtom RJ, Schultz M. Recent studies in primary pulmonary hypertension, including pharmacodynamic observations on pulmonary vascular resistance. Bull N Y Acad Med. 1954;30(3):195-207.

22. Navas $P$, et al. Molecular analysis of BMPR2, TBX4, and KCNK3 and genotype-phenotype correlations in Spanish patients and families with idiopathic and hereditary pulmonary arterial hypertension. Rev Esp Cardiol (Engl Ed). 2016;69(11):1011-9.

23. Soubrier F, et al. Genetics and genomics of pulmonary arterial hypertension. Turk Kardiyol Dern Ars. 2014;42(Suppl 1):17-28.

24. Pousada G, et al. Novel mutations in BMPR2, ACVRL1 and KCNA5 genes and hemodynamic parameters in patients with pulmonary arterial hypertension. PLOS ONE. 2014;9(6):e100261.

25. Ma L, Chung WK. The genetic basis of pulmonary arterial hypertension. Hum Genet. 2014;133(5):471-9.

26. Nichols WC, et al. Localization of the gene for familial primary pulmonary hypertension to chromosome 2q31-32. Nat Genet. 1997;15(3):277-80.

27. Morse JH, et al. Mapping of familial primary pulmonary hypertension locus (PPH1) to chromosome 2q31-q32. Circulation. 1997;95(12):2603-6.

28. van der Bruggen CE, et al. Bone morphogenetic protein receptor type 2 mutation in pulmonary arterial hypertension: a view on the right ventricle. Circulation. 2016;133(18):1747-60.

29. Evans JD, et al. BMPR2 mutations and survival in pulmonary arterial hypertension: an individual participant data meta-analysis. Lancet Respir Med. 2016;4(2):129-37.

30. Kabata $H$, et al. Bone morphogenetic protein receptor type 2 mutations, clinical phenotypes and outcomes of Japanese patients with sporadic or familial pulmonary hypertension. Respirology. 2013;18(7):1076-82.

31. Loyd JE, et al. Genetic anticipation and abnormal gender ratio at birth in familial primary pulmonary hypertension. Am J Respir Crit Care Med. 1995;152(1):93-7.

32. Machado RD, et al. BMPR2 haploinsufficiency as the inherited molecular mechanism for primary pulmonary hypertension. Am J Hum Genet. 2001;68(1):92-102. 
33. Rosenzweig EB, et al. Clinical implications of determining BMPR2 mutation status in a large cohort of children and adults with pulmonary arterial hypertension. J Heart Lung Transplant. 2008;27(6):668-74.

34. Foderaro A, Ventetuolo CE. Pulmonary arterial hypertension and the sex hormone paradox. Curr Hypertens Rep. 2016;18(11):84.

35. Ma L, et al. A novel channelopathy in pulmonary arterial hypertension. $\mathrm{N}$ Engl J Med. 2013;369(4):351-61.

36. Mahmoud M, et al. Endoglin and activin receptor-like-kinase 1 are co-expressed in the distal vessels of the lung: implications for two familial vascular dysplasias HHT and PAH. Lab Invest. 2009;89(1):15-25.

37. Shintani $M$, et al. A new nonsense mutation of SMAD8 associated with pulmonary arterial hypertension. J Med Genet. 2009;46(5):331-7.

38. Williams TM, Lisanti MP. The Caveolin genes: from cell biology to medicine. Ann Med. 2004;36(8):584-95.

39. Austin ED, Loyd JE. The genetics of pulmonary arterial hypertension. Circ Res. 2014;115(1):189-202.

40. Abman SH, et al. Executive summary of the American Heart Association and American Thoracic Society joint guidelines for pediatric pulmonary hypertension. Am J Respir Crit Care Med. 2016;194(7):898-906.

41. Abman SH, et al. Pediatric pulmonary hypertension. Guidelines from the American Heart Association and American Thoracic Society. Circulation. 2015;132(21):2037-99.

42. Yamaki S, Wagenvoort CA. Comparison of primary plexogenic arteriopathy in adults and children. A morphometric study in 40 patients. Br Heart J. 1985;54(4):428-34.

43. Kim JD, et al. Epigenetic modulation as a therapeutic approach for pulmonary arterial hypertension. Exp Mol Med. 2015;47(7):e175.

44. Newman JH, et al. Pulmonary arterial hypertension: future directions: report of a National Heart, Lung and Blood Institute/Office of Rare Diseases workshop. Circulation. 2004;109(24):2947-52.

45. Durmowicz AG, Stenmark KR. Mechanisms of structural remodeling in chronic pulmonary hypertension. Pediatr Rev. 1999;20(11):e91-102.

46. Budhiraja R, Tuder RM, Hassoun PM. Endothelial dysfunction in pulmonary hypertension. Circulation. 2004;109(2):159-65.
47. Boehme J, et al. Pulmonary artery smooth muscle cell hyperproliferation and metabolic shift triggered by pulmonary overcirculation. Am J Physiol Heart Circ Physiol. 2016;311(4):H944-57.

48. Voelkel NF, et al. Pathobiology of pulmonary arterial hypertension and right ventricular failure. Eur Respir J. 2012;40(6):1555-65.

49. Peng $\mathrm{H}$, et al. The Warburg effect: a new story in pulmonary arterial hypertension. Clin Chim Acta. 2016;461:53-8.

50. Hoeper $\mathrm{MM}$, et al. Imatinib mesylate as add-on therapy for pulmonary arterial hypertension: results of the randomized IMPRES study. Circulation. 2013;127(10):1128-38.

51. Ghofrani HA, et al. Imatinib in pulmonary arterial hypertension patients with inadequate response to established therapy. Am J Respir Crit Care Med. 2010;182(9):1171-7.

52. Dasanu CA, et al. Cardiovascular toxicity associated with small molecule tyrosine kinase inhibitors currently in clinical use. Expert Opin Drug Saf. 2012;11(3):445-57.

53. Montani D, et al. Pulmonary arterial hypertension in patients treated by dasatinib. Circulation. 2012;125(17):2128-37.

54. Scognamiglio G, et al. C-reactive protein in adults with pulmonary arterial hypertension associated with congenital heart disease and its prognostic value. Heart. 2014;100(17):1335-41.

55. Hassoun PM, et al. Inflammation, growth factors, and pulmonary vascular remodeling. J Am Coll Cardiol. 2009;54(1 Suppl):S10-9.

56. Said K. Anticoagulation in pulmonary arterial hypertension: contemporary data from COMPERA registry. Glob Cardiol Sci Pract. 2014;2014(2):48-52.

57. Olsson KM, et al. Anticoagulation and survival in pulmonary arterial hypertension: results from the comparative, prospective registry of newly initiated therapies for pulmonary hypertension (COMPERA). Circulation. 2014;129(1):57-65.

58. Wagenvoort CA. The pathology of primary pulmonary hypertension. J Pathol. 1970; 101(4):Pi. doi:10.1002/path.1711010408.

59. Heath D, Edwards JE. Configuration of elastic tissue of pulmonary trunk in idiopathic pulmonary hypertension. Circulation. 1960;21:59-62.

60. Wilson KL, et al. Persistent pulmonary hypertension of the newborn is associated with mode of delivery and not with maternal use of selective 
serotonin reuptake inhibitors. Am J Perinatol. 2011;28(1):19-24.

61. Sluiter I, et al. Vascular abnormalities in human newborns with pulmonary hypertension. Expert Rev Respir Med. 2011;5(2):245-56.

62. Reece EA, et al. Persistent pulmonary hypertension: assessment of perinatal risk factors. Obstet Gynecol. 1987;70(5):696-700.

63. Francis $\mathrm{SH}$, et al. cGMP-dependent protein kinases and cGMP phosphodiesterases in nitric oxide and cGMP action. Pharmacol Rev. 2010;62(3):525-63.

64. Shan X, et al. Differential expression of PDE5 in failing and nonfailing human myocardium. Circ Heart Fail. 2012;5(1):79-86.

65. Humpl T, et al. Sildenafil therapy for neonatal and childhood pulmonary hypertensive vascular disease. Cardiol Young. 2011;21(2):187-93.

66. Bowers $\mathrm{R}$, et al. Oxidative stress in severe pulmonary hypertension. Am J Respir Crit Care Med. 2004;169(6):764-9.

67. Dorfmuller $P$, et al. Increased oxidative stress and severe arterial remodeling induced by permanent high-flow challenge in experimental pulmonary hypertension. Respir Res. 2011;12:119.

68. Pierce CM, Krywawych S, Petros AJ. Asymmetric dimethyl arginine and symmetric dimethyl arginine levels in infants with persistent pulmonary hypertension of the newborn. Pediatr Crit Care Med. 2004;5(6):517-20.

69. Bauer M, et al. Selective upregulation of endothelin B receptor gene expression in severe pulmonary hypertension. Circulation. 2002;105(9):1034-6.

70. Sprague RS, et al. Prostacyclin analogs stimulate receptor-mediated cAMP synthesis and ATP release from rabbit and human erythrocytes. Microcirculation. 2008;15(5):461-71.

71. Gryglewski RJ, et al. Arterial walls are protected against deposition of platelet thrombi by a substance (prostaglandin $\mathrm{X}$ ) which they make from prostaglandin endoperoxides. Prostaglandins. 1976;12(5):685-713.

72. Long WA, Rubin LJ. Prostacyclin and PGE1 treatment of pulmonary hypertension. Am Rev Respir Dis. 1987;136(3):773-6.

73. Crosswhite P, Sun Z. Molecular mechanisms of pulmonary arterial remodeling. Mol Med. 2014;20:191-201.
74. Lammers AE, et al. Functional classification of pulmonary hypertension in children: report from the PVRI pediatric taskforce, Panama 2011. Pulm Circ. $2011 ; 1(2): 280-5$.

75. Ploegstra MJ, et al. Growth in children with pulmonary arterial hypertension: a longitudinal retrospective multiregistry study. Lancet Respir Med. 2016;4(4):281-90.

76. Wen L, et al. Frequency of supraventricular arrhythmias in patients with idiopathic pulmonary arterial hypertension. Am J Cardiol. 2014;114(9):1420-5.

77. Izzo A, et al. "Nocturnal Seizures" in idiopathic pulmonary arterial hypertension. J Clin Sleep Med. 2013;9(10):1091-2.

78. Rosenzweig EB, Barst RJ. Pulmonary arterial hypertension in children: a medical update. Curr Opin Pediatr. 2008;20(3):288-93.

79. van Loon R, et al. Clinical characterization of pediatric pulmonary hypertension: complex presentation and diagnosis. J Pediatr. 2009;155(2):176-82.

80. Adatia I, Kothari SS, Feinstein JA. Pulmonary hypertension associated with congenital heart disease: pulmonary vascular disease: the global perspective. Chest. 2010;137(6 Suppl):52S-61S.

81. Levine DJ. Diagnosis and management of pulmonary arterial hypertension: implications for respiratory care. Respir Care. 2006;51(4):368-81.

82. Takatsuki S, Wagner BD, Ivy DD. B-type natriuretic peptide and amino-terminal pro-B-type natriuretic peptide in pediatric patients with pulmonary arterial hypertension. Congenit Heart Dis. 2012;7(3):259-67.

83. Bernus A, et al. Brain natriuretic peptide levels in managing pediatric patients with pulmonary arterial hypertension. Chest. 2009;135(3):745-51.

84. Daniels LB, Maisel AS. Natriuretic peptides. J Am Coll Cardiol. 2007;50(25):2357-68.

85. Lenz AM. Natriuretic peptides in children: physiology and clinical utility. Curr Opin Pediatr. 2011;23(4):452-9.

86. Arya B, et al. Echocardiographic assessment of right atrial pressure in a pediatric and young adult population. Pediatr Cardiol. 2016;37(3):558-67.

87. Wright LM, et al. Follow-up of pulmonary hypertension with echocardiography. JACC Cardiovasc Imaging. 2016;9(6):733-46.

88. Jone PN, et al. Right ventricular to left ventricular diameter ratio at end-systole in evaluating 
outcomes in children with pulmonary hypertension. J Am Soc Echocardiogr. 2014;27(2):172-8.

89. Koestenberger $M$, et al. Right ventricular function in infants, children and adolescents: reference values of the tricuspid annular plane systolic excursion (TAPSE) in 640 healthy patients and calculation of $\mathrm{z}$ score values. J Am Soc Echocardiogr. 2009;22(6):715-9.

90. Forfia PR, Vachiery JL. Echocardiography in pulmonary arterial hypertension. Am J Cardiol. 2012;110(6 Suppl):16s-24s.

91. Groh GK, et al. Doppler echocardiography inaccurately estimates right ventricular pressure in children with elevated right heart pressure. J Am Soc Echocardiogr. 2014;27(2):163-71.

92. Abbas $\mathrm{AE}$, et al. A simple method for noninvasive estimation of pulmonary vascular resistance. J Am Coll Cardiol. 2003;41(6):1021-7.

93. Di Maria MV, et al. Echocardiographic estimation of right ventricular stroke work in children with pulmonary arterial hypertension: comparison with invasive measurements. J Am Soc Echocardiogr. 2015;28(11):1350-7.

94. Barst RJ. Pharmacologically induced pulmonary vasodilatation in children and young adults with primary pulmonary hypertension. Chest. 1986;89(4): 497-503.

95. Douwes JM, et al. Acute vasodilator response in pediatric pulmonary arterial hypertension: current clinical practice from the TOPP registry. J Am Coll Cardiol. 2016;67(11):1312-23.

96. Zhang C, et al. Cardiac catheterization and pulmonary vasoreactivity testing in children with idiopathic pulmonary arterial hypertension. Zhonghua Er Ke Za Zhi. 2014;52(6):468-72.

97. Yung D, et al. Outcomes in children with idiopathic pulmonary arterial hypertension. Circulation. 2004;110(6):660-5.

98. Zuckerman WA, et al. Safety of cardiac catheterization at a center specializing in the care of patients with pulmonary arterial hypertension. Pulm Circ. 2013;3(4):831-9.

99. Barst RJ, et al. Pulmonary arterial hypertension: a comparison between children and adults. Eur Respir J. 2011;37(3):665-77.

100. Garofano RP, Barst RJ. Exercise testing in children with primary pulmonary hypertension. Pediatr Cardiol. 1999;20(1):61-4 (discussion 65).

101. Zapico AG, et al. Predicting peak oxygen uptake from the 6-minute walk test in patients with pulmonary hypertension. J Cardiopulm Rehabil Prev. 2016;36(3):203-8.

102. Frost AE, et al. The 6-min walk test (6 MW) as an efficacy endpoint in pulmonary arterial hypertension clinical trials: demonstration of a ceiling effect. Vascul Pharmacol. 2005;43(1):36-9.

103. Schafer M, et al. Characterization of CMR-derived haemodynamic data in children with pulmonary arterial hypertension. Eur Heart J Cardiovasc Imaging. 2016. doi:10.1093/ehjci/jew152.

104. de Siqueira ME, et al. Characterization and clinical significance of right ventricular mechanics in pulmonary hypertension evaluated with cardiovascular magnetic resonance feature tracking. J Cardiovasc Magn Reson. 2016;18(1):39.

105. Moledina S, et al. Prognostic significance of cardiac magnetic resonance imaging in children with pulmonary hypertension. Circ Cardiovasc Imaging. 2013;6(3):407-14.

106. Tang CX, et al. Multidetector computed tomography pulmonary angiography in childhood acute pulmonary embolism. Pediatr Radiol. 2015;45(10):1431-9.

107. Zacharias C, et al. Pediatric CT: strategies to lower radiation dose. Am J Roentgenol. 2013;200(5): 950-6.

108. Brenner DJ, Hall EJ. Computed tomography-an increasing source of radiation exposure. $\mathrm{N}$ Engl J Med. 2007;357(22):2277-84.

109. del Cerro MJ, et al. Pulmonary hypertension in bronchopulmonary dysplasia: clinical findings, cardiovascular anomalies and outcomes. Pediatr Pulmonol. 2014;49(1):49-59.

110. Horellou $\mathrm{MH}$, et al. Congenital protein $\mathrm{C}$ deficiency and thrombotic disease in nine French families. $\mathrm{Br}$ Med J (Clin Res Ed). 1984;289(6454):1285-7.

111. O'Sullivan J, et al. Protein S deficiency: early presentation and pulmonary hypertension. Arch Dis Child. 1992;67(7):960-1.

112. Santosa F, et al. Pulmonary embolism in young people. Trends in Germany from 2005 to 2011. Hamostaseologie. 2014;34(1):88-92.

113. Hellfritzsch M, Grove EL. Life-threatening contraceptive-related pulmonary embolism in a 14-year-old girl with hereditary thrombophilia. Am J Case Rep. 2015;16:667-9.

114. Colvin KL, et al. Biomarkers for pediatric pulmonary arterial hypertension-a call to collaborate. Front Pediatr. 2014;2:7. 
115. Anwar A, et al. Novel biomarkers for pulmonary arterial hypertension. Respir Res. 2016;17(1):88.

116. Calvo E, Garcia-Alvarez A, Vazquez J. The quest for metabolic biomarkers of pulmonary hypertension. J Am Coll Cardiol. 2016;67(2):190-2.

117. Lewis GD, et al. Metabolic profiling of right ventricular-pulmonary vascular function reveals circulating biomarkers of pulmonary hypertension. J Am Coll Cardiol. 2016;67(2):174-89.

118. Smadja DM, et al. Circulating Endothelial Cells. A new candidate biomarker of irreversible pulmonary hypertension secondary to congenital heart disease. Circulation. 2009;119(3):374-81.

119. Brady MT, et al. Updated guidance for palivizumab prophylaxis among infants and young children at increased risk of hospitalization for respiratory syncytial virus infection. Pediatrics. 2014;134(2): 415-20.

120. Roldan T, et al. Anticoagulation in patients with pulmonary arterial hypertension: an update on current knowledge. J Heart Lung Transplant. 2016;35(2):151-64.

121. Perrin S, et al. Nasal decongestant exposure in patients with pulmonary arterial hypertension: a pilot study. Eur Respir J. 2015;46(4):1211-4.

122. Hansmann G, et al. Executive summary. Expert consensus statement on the diagnosis and treatment of paediatric pulmonary hypertension. The European Paediatric Pulmonary Vascular Disease Network, endorsed by ISHLT and DGPK. Heart. 2016;102(Suppl 2):ii86-100.

123. Ichinose F, Roberts JD, Zapol WM. Inhaled nitric oxide. Circulation. 2004;109(25):3106-11.

124. Roubinian $\mathrm{N}$, et al. Effects of commercial air travel on patients with pulmonary hypertension air travel and pulmonary hypertension. Chest. 2012;142(4): 885-92.

125. Ivy DD, et al. Pediatric pulmonary hypertension. J Am College of Cardiol. 2013;62(25):D117-26.

126. Barst RJ, Maislin G, Fishman AP. Vasodilator therapy for primary pulmonary hypertension in children. Circulation. 1999;99(9):1197-208.

127. Levy M, et al. Add-on therapy with subcutaneous treprostinil for refractory pediatric pulmonary hypertension. J Pediatr. 2011;158(4):584-8.

128. Ferdman DJ, et al. Subcutaneous treprostinil for pulmonary hypertension in chronic lung disease of infancy. Pediatrics. 2014;134(1):e274-8.
129. Krishnan U, et al. Effectiveness and safety of inhaled treprostinil for the treatment of pulmonary arterial hypertension in children. Am J Cardiol. 2012;110(11):1704-9.

130. Chakinala MM, et al. Transition from parenteral to oral treprostinil in pulmonary arterial hypertension. J Heart Lung Transplant. 2017;36(2):193-201.

131. Ivy DD, et al. Short- and long-term effects of inhaled iloprost therapy in children with pulmonary arterial hypertension. J Am Coll Cardiol. 2008;51(2):161-9.

132. Galie N, et al. Effects of beraprost sodium, an oral prostacyclin analogue, in patients with pulmonary arterial hypertension: a randomized, double-blind, placebo-controlled trial. J Am Coll Cardiol. 2002;39(9):1496-502.

133. Barst RJ, et al. Pharmacokinetics, safety, and efficacy of bosentan in pediatric patients with pulmonary arterial hypertension. Clin Pharmacol Ther. 2003;73(4):372-82.

134. Sitbon O, et al. Selexipag for the treatment of pulmonary arterial hypertension. $\mathrm{N}$ Engl J Med. 2015;373(26):2522-33.

135. Rosenzweig EB, et al. Effects of long-term bosentan in children with pulmonary arterial hypertension. J Am Coll Cardiol. 2005;46(4):697-704.

136. Beghetti $\mathrm{M}$, et al. Pharmacokinetic and clinical profile of a novel formulation of bosentan in children with pulmonary arterial hypertension: the FUTURE-1 study. Br J Clin Pharmacol. 2009;68(6): 948-55.

137. Rubin LJ, et al. Bosentan therapy for pulmonary arterial hypertension. N Engl J Med. 2002;346(12): 896-903.

138. Takatsuki S, et al. Clinical safety, pharmacokinetics, and efficacy of ambrisentan therapy in children with pulmonary arterial hypertension. Pediatr Pulmonol. 2013;48(1):27-34.

139. Pulido T, et al. Macitentan and morbidity and mortality in pulmonary arterial hypertension. N Engl J Med. 2013;369(9):809-18.

140. Abman SH, et al. Implications of the U.S. Food and Drug Administration warning against the use of sildenafil for the treatment of pediatric pulmonary hypertension. Am J Respir Crit Care Med. 2013;187(6):572-5.

141. Barst RJ, et al. A randomized, double-blind, placebo-controlled, dose-ranging study of oral sildenafil citrate in treatment-naive children with 
pulmonary arterial hypertension. Circulation. 2012;125(2):324-34.

142. Barst RJ, et al. STARTS-2: long-term survival with oral sildenafil monotherapy in treatment-naive pediatric pulmonary arterial hypertension. Circulation. 2014;129(19):1914-23.

143. Palma G, et al. Sildenafil therapy for pulmonary hypertension before and after pediatric congenital heart surgery. Tex Heart Inst J. 2011;38(3):238-42.

144. Lee JE, Hillier SC, Knoderer CA. Use of sildenafil to facilitate weaning from inhaled nitric oxide in children with pulmonary hypertension following surgery for congenital heart disease. J Intensive Care Med. 2008;23(5):329-34.

145. Namachivayam $P$, et al. Sildenafil prevents rebound pulmonary hypertension after withdrawal of nitric oxide in children. Am J Respir Crit Care Med. 2006;174(9):1042-7.

146. Humbert M, Sitbon O, Simonneau G. Treatment of pulmonary arterial hypertension. $\mathrm{N}$ Engl J Med. 2004;351(14):1425-36.

147. Simonneau G, et al. Incident and prevalent cohorts with pulmonary arterial hypertension: insight from SERAPHIN. Eur Respir J. 2015;46(6):1711-20.

148. Galiè $\mathrm{N}$, et al. Updated treatment algorithm of pulmonary arterial hypertension. J Am Coll Cardiol. 2013;62(25):D60-72.

149. Humbert M, et al. Combination of bosentan with epoprostenol in pulmonary arterial hypertension: BREATHE-2. Eur Respir J. 2004;24(3):353-9.

150. Zijlstra WM, et al. Clinical classification in pediatric pulmonary arterial hypertension associated with congenital heart disease. Pulm Circ. 2016;6(3):302-12.

151. Gurtu V, Michelakis ED. Emerging therapies and future directions in pulmonary arterial hypertension. Can J Cardiol. 2015;31(4):489-501.

152. Rabinovitch M. Pathobiology of pulmonary hypertension. Annu Rev Pathol. 2007;2:369-99.

153. Spiekerkoetter E. FK506 activates BMPR2, rescues endothelial dysfunction, and reverses pulmonary hypertension. J Clin Investig. 2013;123(8):3600-13.

154. Satoh K, Fukumoto Y, Shimokawa H. Rho-kinase: important new therapeutic target in cardiovascular diseases. Am J Physiol Heart Circ Physiol. 2011;301(2):H287-96.
155. Doe Z, et al. Evidence for Rho-kinase activation in patients with pulmonary arterial hypertension. Circ J. 2009;73(9):1731-9.

156. Fukumoto $Y$, et al. Acute vasodilator effects of a Rho-kinase inhibitor, fasudil, in patients with severe pulmonary hypertension. Heart. 2005;91(3): 391-2.

157. Chen S-L, et al. Pulmonary artery denervation to treat pulmonary arterial hypertensionthe single-center, prospective, first-in-man padn-1 study (first-in-man pulmonary artery denervation for treatment of pulmonary artery hypertension). J Am Coll Cardiol. 2013;62(12):1092-100.

158. Chen SL, et al. Hemodynamic, functional, and clinical responses to pulmonary artery denervation in patients with pulmonary arterial hypertension of different causes: phase II results from the pulmonary artery denervation-1 study. Circ Cardiovasc Interv. 2015;8(11):e002837.

159. Kerstein D, et al. Blade balloon atrial septostomy in patients with severe primary pulmonary hypertension. Circulation. 1995;91(7):2028-35.

160. Al Maluli $\mathrm{H}$, et al. Atrial septostomy: a contemporary review. Clin Cardiol. 2015;38(6): 395-400.

161. Chiu JS, et al. Balloon atrial septostomy in pulmonary arterial hypertension: effect on survival and associated outcomes. J Heart Lung Transplant. 2015;34(3):376-80.

162. Baruteau AE, et al. Potts shunt in children with idiopathic pulmonary arterial hypertension: long-term results. Ann Thorac Surg. 2012;94(3): 817-24.

163. Grady RM, Eghtesady P. Potts shunt and pediatric pulmonary hypertension: what we have learned. Ann Thorac Surg. 2016;101(4):1539-43.

164. Chicotka S, et al. The "Central Sport Model": extracorporeal membrane oxygenation using the innominate artery for smaller patients as bridge to lung transplantation. Asaio J. 2016. doi:10.1097/ MAT.0000000000000427.

165. Kirkby S, Hayes D. Pediatric lung transplantation: indications and outcomes. J Thorac Dis. 2014;6(8):1024-31.

166. Sliwa K, et al. Pulmonary hypertension and pregnancy outcomes: data from the Registry Of Pregnancy and Cardiac Disease (ROPAC) of the European Society of Cardiology. Eur J Heart Fail. 2016;18(9):1119-28. 
167. Terek D, et al. Pulmonary arterial hypertension and pregnancy. J Res Med Sci. 2013;18(1):73-6.

168. Weiss BM, et al. Outcome of pulmonary vascular disease in pregnancy: a systematic overview from 1978 through 1996. J Am Coll Cardiol. 1998;31(7): 1650-7.
169. Agerstrand C, et al. Extracorporeal membrane oxygenation for cardiopulmonary failure during pregnancy and postpartum. Ann Thorac Surg. 2016;102(3):774-9. 